\title{
The effects of transport infrastructure on regional economic development: A simulated spatial overlapping generations model with heterogenous skill
}

\author{
loannis Tikoudis \\ Marcus Sundberg \\ Anders Karlström \\ Royal Institute of Technology ${ }^{a}$ Royal Institute of Technology ${ }^{b} \quad$ Royal Institute of Technology ${ }^{c}$
}

\begin{abstract}
As a result of public investment, lower freight transport costs tend to translate into lower local price indices and are associated with equilibria characterized by higher output and consumption. In this paper we investigate an additional effect to these trade gains, namely the gains from better spatial matching in the labor market. We simulate a two-region Spatial OLG model in which agents are heterogeneous in terms of skill. Under repeated simulation experiments, we show that, for high household relocation frictions, the possibility of interregional commuting can be seen as an alternative way to realize the potential matching effects. For high levels of skill heterogeneity and a plausible parametric input, a steady state in which labor matching is realized through commuting can be associated with up to $10 \%$ higher per capita output, compared to the one with homogenous labor, in which only gains from trade are feasible.
\end{abstract}

Keywords: Economic development; Trade; Freight transportation; Regional economy

\section{Introduction}

Upgrades in transport infrastructure decrease the cost of moving both goods and people. The identification of the various channels through which investment in such infrastructure might affect growth on regional or national level is an important part of the discussion that revolves around the real value of such investments. This paper investigates the above effect from a new perspective. More specifically, we look at how updates in transport infrastructure affect the per capita output through two channels: i) better terms of trade because of lower freight costs, and ii) improved efficiency in the labormarket through matching effects.

Decreasing trade costs tend to increase the demand for a region's product; this effect is manifested in the first channel. The mechanism in the second channel, through matching effects, is less straightforward. As the frictions associated with commuting are reduced, the spatial extent of the labor market enlarges. Any given individual may take into consideration longer commuting distances, given the shorter commuting times. The individual experiences an enlarged spatial la-

${ }^{a}$ Division of Transport and Location Analysis, Department of TransportScience, ioannis.tikoudis@abe.kth.se

${ }^{b}$ Division of Transport and Location Analysis, Department of TransportScience,marcuss@infra.kth.se

${ }^{c}$ Division of Transport and Location Analysis, Department of TransportScience, andersk@infra.kth.se bor market, improving her chance of finding a job that better matches her skill. As a result, the worker might end up in a job where her marginal productivity of labor is higher than before. If this is true for a large number of workers, the transport project might cause a spatial reallocation of labor in a way that the overall productivity of labor in the economy increases. In order to capture the magnitude of this reallocation, we need a model with heterogenous, in terms of labor productivity, matches between workers and firms. This paper introduces this idea into a formal framework.

Neglecting matching effects might lead to erroneous conclusions regarding the regional economic impact of transport infrastructure investments. Furthermore, the separation of matching gains from trade gains could be a useful tool in comparing alternative policies that involve public spending. For instance, a local government might be interested in subsidizing training programs in order to raise labor productivity in local firms. Knowing the magnitude of the matching gains from the investment in transport infrastructure might help the local authority to compare the two policies.

There is an expanding literature on the channels through which infrastructure might affect growth. For an overview of economic models which investigate this relationship on regional level, see Oosterhaven and Knaap (2003) and Rietveld (1989); on national level, there is the survey by Agenor and Moreno-Dodson (2006). Rioja (1999) develops a non-spatial

Copyright 2012 Ioannis Tikoudis, Marcus Sundberg, and Anders Karlström.

Licensed under the Creative Commons Attribution - NonCommercial License 3.0. 
dynamic general equilibrium framework to study the effects of investment in public infrastructure on GDP and welfare, with measures of government investment in infrastructure obtained from actual data sets for seven Latin American countries. Despite the fact that labor mobility has been identified as a contributor to regional growth, to the authors' knowledge, matching effects have not received adequate attention in spatial general equilibrium analysis.

However, a plethora of General Equilibrium models that incorporate at least some of the elements of land, labor mobility, transport and investment in infrastructure, which constitute the main ingredients of our model, have been proposed in the literature. Zhu et al. (2009) develop a two region dynamic Spatial General Equilibrium model with an endogenous efficiency wage setting mechanism (Shapiro and Stiglitz 1984) in order to compute the effects of infrastructure projects on the regional and national unemployment rate. Their main results indicate that regional unemployment may go up or down but it decreases on the national level. The model suggests that the indirect effects from infrastructure improvements that transmit to the regional labor markets account for 10 to 20 percent of the direct effects.

Abdel-Rahman and Wang (1995) construct a matching, core-periphery GE model in which skilled and unskilled labor coexist; wages are determined by Nash bargaining for the skilled and competitively for the unskilled labor force. The model is able to replicate interregional wage disparities and form a local system of cities with a core metropolis emerging due to large matching externalities. Seung and Kraybill (2001) propose a model in which provision of public capital is subject to congestion effects, which depend on the level of private capital in the economy. Anas and Liu (2007) present a model that equilibrates floor space, land and labor markets, output, construction, and commuting for the greater metropolitan area of Chicago. Finally, Artige (2004) provides a model with land, human capital and increasing returns to scale.

This paper introduces F.R.O.G. ${ }^{1}$, a Spatial Overlapping Generations platform to investigate the stated problem by combining several features from the above sources in a framework with different assumptions about the level of heterogeneity in the labor market. The model is able to isolate the matching effects of investment in public infrastructure by: i) computing the difference between the actual output, produced with heterogenous labor, and that produced in a counterfactual state, i.e., in a world with homogenous labor, and ii) comparing this difference for various levels of public infras-

\footnotetext{
${ }^{1}$ F.R.O.G stands for: Framework for the development of Regional Overlapping Generation models
}

tructure. Our model moves entirely inside the Computable General Equilibrium tradition, but incorporates some innovative characteristics beyond labor heterogeneity.

First, we depart from the traditional representative household setting by introducing several simulated households with heterogenous skill endowments. This increases the level of flexibility in the model, since the fairly restrictive assumptions on income effects are dropped; unfortunately, this flexibility is coupled with a cost in terms of computational tractability. Second, the infinitely living agents are replaced by overlapping generations, which face different constraints throughout the transition path and whose members do not necessarily internalize the costs and benefits of the infrastructure investment. In this framework, we perform a division of total gains into trade and matching effects for a plausible parametric input.

\section{Model}

We propose a Spatial Overlapping Generations Model for two regions, in which agents live for two periods. Lifetime utility maximization takes place in three different levels. In the upper level, the relevant choice of the individual is the region of labor supply and housing location in each time period. In the middle level, the individual allocates time optimally between leisure and work and determines the optimal level of total expenditure in each period, given the choice of residential and working zone of the upper level. Savings are implicitly determined at this stage through the optimal levels of consumption and labor. Finally, in the lower level the individual allocates the total expenditure (decided in the middle level) into the commodities produced in the two zones and housing.

There is one representative firm located in each zone, which is assumed to be a myopic profit maximizer that produces output from capital and effective labor units under constant returns to scale. The output is sold both in the local and the interregional market. Exporting the output implies a transport cost which, due to a perfectly elastic supply curve, is transmitted to the consumers of the foreign market. All output markets are characterized by perfect competition. Preferences are assumed to be identical in the two zones. The output produced in each zone is heterogenous, since firms are assumed to be heterogenous across geographic regions. This heterogeneity stems from unobserved differences in production that persist over time in the two zones, i.e., errors from the aggregation of different types of labor into one, cultural factors involved in production, legal and other constraints correlated with the geographic region of production. Each individual is endowed with a region-specific idiosyncratic skill shock which measures 
how efficiently the individual's skill is supplied in the representative firm of each region. The population variance of the idiosyncratic skill distribution highlights the level of skill heterogeneity in the model. This distribution gives rise to migration or commuting between the two regions.

There is a government which taxes labor income and invests in the only form of public capital in the model, a link between the two zones. Transport costs and commuting times are dependent on the amount of capital invested in the link.

\subsection{Consumers}

In our canonical Overlapping Generations framework, individual choice is assumed to take place in three different levels, for each of the two generations alive in the model and for any arbitrary time period $t$. We refer to these levels as upper, middle and bottom level. In the upper level (section 2.1.1), young individuals choose their residential, employment and retirement location simultaneously; the choice of the retirement location is based on the information held at time $t$ and on the beliefs formed about period $t+1$, i.e., when the young individual becomes old; this choice does not involve commitment with respect to retirement location. In the same level, the old individuals retire and reoptimize their plan formed at time $t-1$, i.e., when they were young. Old individuals do not work.

In the middle level optimization problem (section 2.1.2), young individuals engage in the choice of consumption and leisure streams, conditional on the joint choice of their residence, employment and future retirement locations of the upper level choice problem. The upper level choice generates the alternative specific budget and time constraints. In the same level, old individuals just consume their accumulated savings from period $t-1$, conditional on their retirement location choice which imposes the respective alternative specific budget constraint.

In the lower level optimization part (section 2.1.3), we divide the composite demanded quantity of the middle level into demand for each of the two regional goods and housing. Both regional goods are essential in each region, i.e., the preference relation accommodates the Armington (1969) assumption. We assume that individuals consume only in their residential (retirement) zone. The regional price index of the composite consumption has to be derived as a unit cost function from an expenditure minimization problem which is specific to residential (retirement) zone. This part ensures that the choice between labor and leisure is consistent with the detailed consumption plan for the two regional goods and land.

\subsubsection{Discrete joint zone choice}

For the young generation, which consists of the set of individuals $Y$, the upper level choice is considered to be a selection of a discrete alternative that consists of a residential zone $i$, employment zone $j$ and future retirement zone $r$ among a set of all such possible alternatives. Denote an arbitrary alternative by the vector $\mathbf{a}=(i, j, r)$, where $i, j$, and $r$ are chosen from the sets of residential, employment and retirement zones, that is $I, J$ and $R$ respectively. The choice set $A$ is a set that contains all vectors that can be constructed from $I, J$ and $R$; that is $A=I \times J \times R=\{(i, j, r): i \in I, j \in J, r \in R\}$.

Our model refers to a two region world, i.e., $N_{I}=N_{J}=$ $N_{R}=2$, where the geographic regions coincide ${ }^{2}$. The conditional on a indirect utility of any individual $n$ who was born in region $b$ and is young at time $t$ is:

$$
U_{b n \mathbf{a}}^{t}=V_{b n \mathbf{a}}^{t}+\epsilon_{b n \mathbf{a}}^{t}
$$

where $V_{b n \mathbf{a}}^{t}$ denotes the conditional on a representative indirect utility, i.e., the part of indirect utility which consists of factors known to the researcher. On the other hand, one part of the indirect utility, $\epsilon_{b n a}^{t}$, is due to factors unobserved to the researcher. It is therefore a random variable which can be assumed to follow any distribution across individuals and alternatives. Given this, the optimal choice of the young individual is the alternative $\mathbf{a}^{*} \in A$ which maximizes the conditional indirect utility. That is:

$$
\mathbf{a}^{*}=\mathbf{a}^{*}(t, n, b)=\underset{\mathbf{a} \in A}{\operatorname{argmax}} V_{b n \mathbf{a}}^{t}+\epsilon_{b n \mathbf{a}}^{t}
$$

Similarly, the alternative for the old generation, which consists of the set of individuals $O$, is defined by $\hat{\mathbf{a}}=(r)$ and belongs to the choice set $\hat{A}$; old individuals do not work, but retire in the retirement zone $r$ of their choice. The conditional on $\mathbf{a}$ indirect utility of any individual who was born in region $b$ and is old at time $t$ is:

$$
U_{b n \hat{\mathbf{a}}}^{t}=V_{b n \hat{\mathbf{a}}}^{t}+\epsilon_{b n \hat{\mathbf{a}}}^{t}
$$

and the optimal choice:

$$
\hat{\mathbf{a}}^{*}=\hat{\mathbf{a}}^{*}(t, n, b)=\underset{\hat{\mathbf{a}} \in \hat{A}}{\operatorname{argmax}} V_{b n \hat{\mathbf{a}}}^{t}+\epsilon_{b n \hat{\mathbf{a}}}^{t}
$$

Our next step is to specify the functional forms of the utility functions $V_{b n \mathbf{a}}^{t}$ and $V_{b n \hat{\mathbf{a}}}^{t}$. This is done in the next two sections, where we develop a complete structural model for utility maximization.

\footnotetext{
${ }^{2}$ The $x$-th element of the sets $I, J$ and $R$, point to the same geographic region
} 


\subsubsection{Conditional aggregate Consumption - Leisure choice}

Our task in this section is to construct a utility maximization framework that will provide us with $V_{b n \mathbf{a}}^{t}$ and $V_{b n \hat{\mathbf{a}}}^{t}$. First, consider choosing the action $\mathbf{a}=(i, j, r) \in A$. Given that the individual will live in zone $i$, work in zone $j$ while young and retire in zone $r$ when she becomes old, as a implies, the problem collapses into a lifetime utility maximization under an intertemporal budget constraint and the period specific time constraints.

The intertemporal stochastic budget constraint imposes non positive debt or bequests in the end of the individual's lifetime, i.e., after period $t+1$. Therefore all savings, $S_{b n \mathbf{a}}^{t}$, made in $t$ have to be consumed at $t+1$ :

$$
P_{\mathbf{a}}^{\mathrm{e}(t+1)} C_{b n \mathbf{a}}^{t+1}=\left(1+R^{\mathrm{e}(t+1)}\right) S_{b n \mathbf{a}}^{t}+M_{n}^{\mathrm{e}(t+1)}-F_{\mathbf{a}}^{t+1}
$$

where the savings are:

$$
S_{b n \mathbf{a}}^{t}=\left(1-z^{t}\right) w_{\mathbf{a}}^{t}\left(1+d_{b n \mathbf{a}}\right) L_{b n \mathbf{a}}^{t}+M_{n}^{t}-P_{\mathbf{a}}^{t} C_{b n \mathbf{a}}^{t}-\psi_{\mathbf{a}}^{t}-F_{b \mathbf{a}}^{t}
$$

In equation (5), $P_{\mathbf{a}}^{\mathrm{e}(t+1)}$ denotes the expected price of future consumption $C_{b n \mathbf{a}}^{t+1}$ in retirement zone $r$ at time $t+1, R^{\mathrm{e}(t+1)}$ denotes the expected interest rate at time $t+1, S_{b n \mathbf{a}}^{t}$ the savings of the young individual conditional on the choice of $\mathbf{a}=(i, j, r), M_{n}^{\mathrm{e}(t+1)}$ the expected individual income from land rents at time $t+1$ and $F_{\mathrm{a}}^{t+1}$ the old individual's cost of relocating from the residential region $i$ to retirement region $r$.

In equation (6), $z^{t}$ stands for the labor income tax rate, $w_{\mathrm{a}}^{t}$ for the average regional wage rate per unit of time in region $j, d_{b n a}$ for the individual $n$ 's skill deviation when born in region $b$ and supply labor in region $j,\left(1+d_{b n \mathbf{a}}\right) L_{b n \mathbf{a}}^{t}$ the young individual's effective labor supply in units of time, $M_{n}^{t}$ for the current individual rental income, $P_{\mathrm{a}}^{t}$ for the price of current consumption, $C_{b n \mathbf{a}}^{t}$, in region $i, \psi_{\mathbf{a}}^{t}$ for the period commuting costs from the residential zone $i$ to employment zone $j$ and $F_{b \text { a }}^{t}$ for the young individual's cost of relocating her residence from the birth zone $b$ to residential zone $i$.

The alternative $\mathbf{a}$ imposes a time constraint on the young individual, by fixing an alternative specific commuting time to $v_{\mathrm{a}}^{t}$. For any $t$ :

$$
L_{b n \mathbf{a}}^{t}+\ell_{b n \mathbf{a}}^{t}+v_{\mathbf{a}}^{t}=\bar{T}
$$

That is, the sum of the individual labor supply, $L_{b n a}^{t}$, indi- vidual leisure time, $\ell_{b n a}^{t}$, and alternative specific commuting time, $v_{\mathbf{a}}^{t}$, have to sum up to the period time endowment, $\bar{T}$. Since the young individuals will neither supply labor, nor commute at time $t+1$, when they will be old:

$$
\ell_{b n \mathbf{a}}^{t+1}=\bar{T}
$$

We are now ready to declare the young individual's utility maximization problem, conditional on the choice of a. Assuming time separability, adopting a Canonical Overlapping Generations model Acemoglu (2009) and normalizing the period's time endowment to 1 the problem becomes:

$$
\begin{aligned}
\max _{\left(C_{b n \mathbf{a}}^{t}, C_{b n \mathbf{a}}^{t+1}, L_{b n \mathbf{a}}^{t}\right)} u & =\vartheta+\varphi_{0} \log \left(C_{b n \mathbf{a}}^{t}\right)+\varphi_{1} \log \left(1-L_{b n \mathbf{a}}^{t}-v_{\mathbf{a}}^{t}\right) \\
& +\delta\left\{\vartheta+\varphi_{0} \log \left(C_{b n \mathbf{a}}^{t+1}\right)\right\}
\end{aligned}
$$

which is subject to the constraint in (5) and a non-negativity constraint for the conditional to a labor supply decision, $L_{b n \mathbf{a}}^{t}$. The origin specific constant, $\vartheta$, incorporates the mean effect of all unobserved factors that correlate with $\mathbf{a}$; we assume that these constitute social variables that are associated with the individual's origin, i.e., birth zone. The combination of zones for residence, employment and retirement, encapsulated in a, gives rise to a conditional Euler equation of intertemporal consumption which is also individual specific. Setting up the Lagrangian and taking the first order conditions with respect to consumption in periods $t$ and $t+1$ yields:

$$
\frac{C_{b n \mathbf{a}}^{t+1 *}}{C_{b n \mathbf{a}}^{t *}}=\delta\left(1+R^{\mathbf{e} t+1}\right) \frac{P_{\mathbf{a}}^{t}}{P_{\mathbf{a}}^{\mathbf{e} t+1}}
$$

For any given set of expectations, the system of non-linear first order conditions of the problem in (9) can be solved for the conditional Marshalian demands for consumption in the two periods $\left(C_{b n \mathbf{a}}^{t *}, C_{b n \mathbf{a}}^{t+1 *}\right)$, the optimal labor supply, $L_{b n \mathbf{a}}^{t *}$, and the Lagrangian multipliers $\lambda$ and $\mu$ which are attached to the budget constraint and the non negative labor supply condition respectively. Plugging the optimal consumption stream and labor supply in the utility function in (9) yields:

$$
\begin{aligned}
V_{b n \mathbf{a}}^{t} & =\vartheta+\varphi_{0} \log \left(C_{b n \mathbf{a}}^{t *}\right) \\
& +\varphi_{1} \log \left(1-L_{b n \mathbf{a}}^{t *}-v_{\mathbf{a}}^{t}\right)+\delta\left\{\vartheta+\varphi_{0} \log \left(C_{b n \mathbf{a}}^{* t+1}\right)\right\}
\end{aligned}
$$

which is the deterministic part of the conditional indirect 
utility function in (1). This utility can now be written as:

$$
\begin{aligned}
U_{b n \mathbf{a}}^{t} & =\vartheta+\varphi_{0} \log \left(C_{b n \mathbf{a}}^{t *}\right)+\varphi_{1} \log \left(1-L_{b n \mathbf{a}}^{t *}-v_{\mathbf{a}}^{t}\right) \\
& +\delta\left\{\vartheta+\varphi_{0} \log \left(C_{b n \mathbf{a}}^{* t+1}\right)\right\}+\epsilon_{b n \mathbf{a}}^{t}
\end{aligned}
$$

We now turn to the old individual, who has saved some of her income in period $t-1, S^{t-1}$, and retires in zone $r$ at time $t$. Note again that the individual does not commit on $r$ when young. The maximization problem is:

$$
\max _{C_{b n \hat{\mathbf{a}}}^{t}} u=\vartheta+\varphi_{0} \log \left(C_{b n \hat{\mathbf{a}}}^{t}\right)
$$

Which is subject to the budget constraint:

$$
C_{b n \hat{\mathbf{a}}}^{t *}=\frac{\left(1+R^{t}\right) S_{n}^{t-1}+M_{n}^{t}-F_{\hat{\mathbf{a}}}^{t}}{P_{\hat{\mathbf{a}}}^{t}}
$$

Plugging (14) into (13) and combining with (3) yields the conditional indirect utility for the old:

$$
U_{b n \hat{\mathbf{a}}}^{t}=\vartheta+\varphi_{0} \log \left\{\frac{\left(1+R^{t}\right) S_{n}^{t-1}+M_{n}^{t}-F_{\hat{\mathbf{a}}}^{t}}{P_{\hat{\mathbf{a}}}^{t}}\right\}+\epsilon_{b n \hat{\mathbf{a}}}^{t}
$$

In the next section we construct a submodel that disaggregates the composite demand, $C$, and derive the regional consumer price index, $P$, from an expenditure minimization problem.

\subsubsection{Conditional disaggregated consumption}

In this subsection we i) set up a model for the division of the consumption decision into housing (land) and the regional goods produced in the model, and ii) derive the regional price index. We assume that the preference relation satisfies the condition of functional separability with respect to time and between consumption and leisure, i.e., the preferred basket at time $t$ is independent of leisure and the preferred basket at time $t+1$.

The consumption subutility $C$ is Cobb-Douglas, homogenous of degree 1 and thus homothetic:

$$
C_{b n \mathbf{a}}^{t}=\left(x_{0(b n \mathbf{a})}^{t}\right)^{\zeta}\left(x_{1(b n \mathbf{a})}^{t}\right)^{\theta}\left(l_{b n \mathbf{a}}^{t}\right)^{\eta}
$$

where $x_{O(b n \mathbf{a})}^{t}$ and $x_{1(b n \mathbf{a})}^{t}$ refer to conditional on $\mathbf{a}$, current individual demands for the regional goods produced in zone 0 and 1 respectively, and $l_{b n \mathbf{a}}^{t}$ the conditional on a demand for land. We assume homogeneity of degree 1, i.e., $\zeta+\theta+\eta=1$. We can set up the cost minimization problem ${ }^{3}$ :

$$
\begin{aligned}
\text { Min } \quad e_{b n \mathbf{a}}^{t} & =p_{0 \mathbf{a}}^{t} x_{0(b n \mathbf{a})}^{t}+p_{1 \mathbf{a}}^{t} x_{1(b n \mathbf{a})}^{t}+q_{\mathbf{a}}^{t} l_{b n \mathbf{a}}^{t} \\
\text { subject to } \quad C_{b n \mathbf{a}}^{t} & =1
\end{aligned}
$$

whose solution gives rise to the Hicksian demand functions for land and the two regional goods in region $i$ :

$$
\begin{aligned}
x_{0(b n \mathbf{a})}^{t *}\left(p_{0 \mathbf{a}}^{t}, p_{1 \mathbf{a}}^{t}, q_{\mathbf{a}}^{t} ; 1\right) & =\frac{p_{0 i}^{t \zeta-1} p_{1 i}^{t \theta} q_{i}^{t \eta}}{\zeta^{\zeta-1} \theta^{\theta} \eta^{\eta}} \\
x_{1(b n \mathbf{a})}^{t *}\left(p_{0 \mathbf{a}}^{t}, p_{1 \mathbf{a}}^{t}, q_{\mathbf{a}}^{t} ; 1\right) & =\frac{p_{0 i}^{t \zeta} p_{1 i}^{t \theta-1} q_{i}^{t \eta}}{\zeta^{\zeta} \theta^{\theta-1} \eta^{\eta}} \\
l_{b n \mathbf{a}}^{t *}\left(p_{0 \mathbf{a}}^{t}, p_{1 \mathbf{a}}^{t}, q_{\mathbf{a}}^{t} ; 1\right) & =\frac{p_{0 i}^{t \zeta} p_{1 i}^{t \theta} q_{i}^{t \eta-1}}{\zeta^{\zeta} \theta^{\theta} \eta^{\eta-1}}
\end{aligned}
$$

and the regional price index:

$$
P_{i}^{t}=e_{b n \mathbf{a}}^{t *}\left(p_{0 \mathbf{a}}^{t}, p_{1 \mathbf{a}}^{t}, q_{\mathbf{a}}^{t} ; 1\right)=\frac{p_{0 i}^{t}{ }^{\zeta} p_{1 i}^{t \theta} q_{i}^{t \eta}}{\zeta^{\zeta} \theta^{\theta} \eta^{\eta}}
$$

The unit expenditure is i) independent of individual characteristics, i.e., $e_{b n \mathbf{a}}^{* t}\left(p_{\mathbf{a} 0}^{t}, p_{\mathbf{a} 1}^{t}, q_{\mathbf{a}}^{t} ; 1\right)=e_{\mathbf{a}}^{* t}\left(p_{\mathbf{a} 0}^{t}, p_{\mathbf{a} 1}^{t}, q_{\mathbf{a}}^{t} ; 1\right)$, and ii) depends on the residential region only, i.e., $e_{\mathbf{a}}^{* t}\left(p_{\mathbf{a} 0}^{t}, p_{\mathbf{a} 1}^{t}, q_{\mathbf{a}}^{t} ; 1\right)=e_{i}^{* t}\left(p_{i 0}^{t}, p_{i 1}^{t}, q_{i}^{t} ; 1\right)$.

\subsection{Firms}

Each regional sector consists of a finite number of firms that produce a homogenous good, using effective labor units and capital as their sole inputs. We assume that the assumptions of the representative firm theorem, i.e., competitive markets and absence of production externalities, hold; then the economy admits a regional representative firm (Acemoglu 2009), with production function:

$$
X_{j}^{t}=\left(K_{j}^{t}\right)^{\alpha}\left(L_{j}^{t}\right)^{\beta}
$$

\footnotetext{
${ }^{3}$ The cost minimization problem for the old generation is analogous
} 
where $K$ stands for the capital input and $L$ for the use of labor, measured in effective time units. We assume constant returns to scale, or $\alpha+\beta=1$. The output can not be stored and sold in a future period and firms are myopic, i.e., they cannot foresee future prices and wages. A model with dynamic optimizing firms, fixed costs and relocation frictions is left as a topic of future research.

The standard assumption for perfect competition, $p_{j}^{t}=M C\left(X_{j}^{t}\right)$ cannot provide a unique sector supply in the special case of constant returns. Instead, the representative firm accommodates any demand at a price given by the constant marginal cost. The conditional factor demand functions from the cost minimization problem are:

$$
\begin{aligned}
& L_{j \mathbf{D}}^{t}\left(w_{j}^{t}, R^{t} ; X_{j}^{t}\right)^{*}=X_{j}^{t}\left\{\frac{R^{t}}{w_{j}^{t}} \frac{\beta}{\alpha}\right\}^{\alpha} \\
& K_{j \mathbf{D}}^{t}\left(w_{j}^{t}, R^{t} ; X_{j}^{t}\right)^{*}=X_{j}^{t}\left\{\frac{w_{j}^{t}}{R^{t}} \frac{\alpha}{\beta}\right\}^{\beta}
\end{aligned}
$$

and give rise to the cost function:

$$
C_{j}^{t}\left(w_{j}^{t}, R^{t} ; X_{j}^{t}\right)^{*}=X_{j}^{t}\left(R^{t}\right)^{\alpha}\left(w_{j}^{t}\right)^{\beta}\left\{\left(\frac{\beta}{\alpha}\right)^{\alpha}+\left(\frac{\alpha}{\beta}\right)^{\beta}\right\}
$$

The profit maximization condition yields the equilibrium market price in region $j$ :

$$
p_{j}^{t}=M C\left(X_{j}^{t}\right)=\left(R^{t}\right)^{\alpha}\left(w_{j}^{t}\right)^{\beta}\left\{\left(\frac{\beta}{\alpha}\right)^{\alpha}+\left(\frac{\alpha}{\beta}\right)^{\beta}\right\}
$$

It is also the case that, due to the fact that marginal cost is constant, (26) is also a zero profit condition. It is easy to show, using the fact that the Lagrange multiplier of the cost minimization problem formulation equals the marginal cost and the marginal revenue at the optimum, that the conditional factor demands in (23) and (24) are also unconditional in the profit maximizing level of output.

The representative firm exports the output to zones outside $j$. In order to avoid modeling an explicit transport sector, we adopt the Samuelson's iceberg principle (Samuelson 1954). That is, we assume that on the way from the manufacturing zone $j$ to residential zone $i$ that imports the good, only the fraction $\frac{1}{Q_{j i}}$ of the exported quantity survives 'melting' and reaches the destination $i$. We refer to this as the iceberg fraction. Its reciprocal, $Q_{j i}$, is interpreted as the necessary production of output in region $j$ per unit of received output in region $i$. Therefore, for each region $i$ other than $j$, (25) becomes:

$$
C_{j i}^{t *}\left(w_{j}^{t}, R^{t}, Q_{j i} ; X_{i}^{t}\right)=Q_{j i} X_{i}^{t}\left(R^{t}\right)^{\alpha}\left(w_{j}^{t}\right)^{\beta}\left\{\left(\frac{\beta}{\alpha}\right)^{\alpha}+\left(\frac{\alpha}{\beta}\right)^{\beta}\right\}
$$

and the marginal cost pricing rule in (26) becomes:

$$
p_{j i}^{t}=M C\left(X_{j i}^{t}\right)=Q_{j i}\left(R^{t}\right)^{\alpha}\left(w_{j}^{t}\right)^{\beta}\left\{\left(\frac{\beta}{\alpha}\right)^{\alpha}+\left(\frac{\alpha}{\beta}\right)^{\beta}\right\}
$$

Note that, from (26) and (28), it can be shown that the difference between the market prices of the same good in a distant market and its home market is $\left(Q_{j i}-1\right) p_{j}^{t}$, which implies that the entire transport cost is transferred to the consumers of region $i$. This effect, which is similar to tax effects in equilibrium analysis, is a direct result of the CRS assumption in production that gives rise to a perfectly elastic supply curve.

\subsection{Government and Transport System}

There is a simplified transport system in the model, summarized by a link between regions 0 and 1 . The link serves the transport of traded goods and makes interregional commuting and migration possible. The iceberg fraction's reciprocal, $Q_{01}^{t}$, and the commuting time between employment zones 0 and $1, v_{01}^{t}$, are decreasing, continuous functions in public capital, $K_{\mathrm{G}}$, while $Q_{01}^{t}$ is also increasing in the volume of interregional trade:

$$
\begin{aligned}
Q_{01}^{t} & =Q_{01}^{t}\left(K_{\mathrm{G}}, \hat{X}_{01}^{t}\right) \\
v_{01}^{t} & =v_{01}^{t}\left(K_{\mathrm{G}}\right)
\end{aligned}
$$

Where $\hat{X}_{01}^{t}$ denotes the volume of interregional trade between regions 0 and 1 (see section 2.4). We are looking for functional forms to specify (29) and (30). For the trade of goods, we generate a new variable:

$$
\hat{k}_{01}^{t}=\left(K_{\mathrm{G}}^{t}\right)^{\omega}\left(\hat{X}_{01}^{t}\right)^{\xi}
$$


to which we refer as public capital adjusted for trade volume. The parameter $\xi$ is able, when set at a value different than zero, to capture the congestion effects that are generated from the volume of trade. Intuitively, at any $\xi>0$ transport costs of producers are interdependent through the use of the, congested, public link. It turns out that the function:

$$
Q_{01}^{t}=Q_{10}^{t}=1+A \hat{k}_{01}^{t}=1+A\left(K_{\mathrm{G}}^{t}\right)^{\omega}\left(\hat{X}_{01}^{t}\right)^{\xi}
$$

concentrates desirable properties of a function that points transport costs to different levels of public infrastructure. It is convex and decreasing in $K_{\mathrm{G}}^{t}$ for $\omega<0$ and $A>0$. Furthermore, if we disregard congestion effects:

$$
\lim _{K_{\mathrm{G}}^{t} \rightarrow \infty} Q_{01}^{t}=1
$$

and:

$$
\lim _{K_{\mathrm{G}}^{t} \rightarrow 0} Q_{01}^{t}=\infty
$$

With $\xi=0$, the elasticity of the iceberg's reciprocal with respect to public capital, which turns out to be of vital importance in the evaluation of the public capital level, is:

$$
\mathscr{E}_{K_{\mathrm{G}}^{t}} Q_{01}^{t}=\frac{\omega A\left(K_{\mathrm{G}}^{t}\right)^{\omega}}{1+A\left(K_{\mathrm{G}}^{t}\right)^{\omega}}
$$

The commuting time between the two zones is assumed to be a function with analogous properties:

$$
v_{01}^{t}=v_{01}^{t}=B\left(K_{\mathrm{G}}^{t}\right)^{\varsigma}
$$

We also assume the existence of government whose sole task is to sustain this link or upgrade it, by collecting the necessary resources in each time period, i.e., buying capital $K_{\mathrm{G}}^{t}$ from the old generation to set up the link and charging workers and firms for interregional commuting, transport of goods and household relocations. The government taxes labor income at rate $z^{t}$, independent of the region. If the govern- ment runs a balanced budget, then the generation infrastructure cost, $R^{t} K_{\mathrm{G}}^{t}$, has to be equal to government income:

$$
\begin{aligned}
R^{t} K_{\mathrm{G}}^{t} & =\sum_{n \in Y}\left\{L_{b n \mathbf{a}^{*}}^{* t}\left(1+d_{b n \mathbf{a}^{*}}\right) w_{\mathbf{a}^{*}}^{t} z^{t}\right\}+\sum_{n \in Y} \psi_{\mathbf{a}^{*}} \\
& +\sum_{n \in Y} F_{b \mathbf{a}^{*}}+\sum_{n \in O} F_{i \hat{\mathbf{a}}^{*}}
\end{aligned}
$$

Where $\mathbf{a}^{*}$ is a short hand notation of the optimal action of a young individual, $\mathbf{a}^{*}(t, n, b)$, and $\hat{\mathbf{a}}^{*}$ is the corresponding short hand notation of the optimal action of an old individual, $\hat{\mathbf{a}}^{*}(t, n, b)$. The first component on the right hand side is the governmental tax revenue, the second is the revenue from commuting fees, and the remaining components refer to revenues from household relocations.

\subsection{Period equilibrium}

We are now stating the conditions for the equilibrium in each time period. For each $t$ the following holds:

The aggregate demand for the good produced in region 0 is the sum of the local demand, $X_{0(0)}^{* t}$, and the demand for imports in region $1, X_{0(1)}^{* t}$. The demand for the local good in region 0 is:

$$
\begin{aligned}
X_{0(0)}^{t *} & =\sum_{n \in Y} \mathrm{I}_{n}\left[\mathbf{a}^{*}: i^{*}=0\right] x_{0\left(b n \mathbf{a}^{*}\right)}^{t *} C_{b n \mathbf{a}^{*}}^{t *} \\
& +\sum_{n \in O} \mathrm{I}_{n}\left[\hat{\mathbf{a}}^{*}: r^{*}=0\right] x_{0\left(b n \hat{\mathbf{a}}^{*}\right)}^{t *} C_{b n \hat{\mathbf{a}}^{*}}^{t *}
\end{aligned}
$$

where $\mathrm{I}_{n}$ is an indicator function that attains the value 1 if the expression in the brackets is true, i.e., if the young(old) individual chooses to reside in region 0 , and $x_{0\left(b n a^{*}\right)}^{t *} C_{b n a^{*}}^{t *}$ is the Marshalian demand ${ }^{4}$ for the good from region 0 . The demand for imports of the same good in region 1 is:

$$
\begin{aligned}
X_{0(1)}^{t *} & =\sum_{n \in Y} \mathrm{I}_{n}\left[\mathrm{a}^{*}: i^{*}=1\right] x_{O\left(b n \mathbf{a}^{*}\right)}^{t *} C_{b n \mathbf{a}^{*}}^{t *} \\
& +\sum_{n \in O} \mathrm{I}_{n}\left[\hat{\mathbf{a}}^{*}: r^{*}=1\right] x_{O\left(b n \hat{\mathbf{a}}^{*}\right)}^{t *} C_{b n \hat{\mathbf{a}}^{*}}^{t *}
\end{aligned}
$$

Similarly, the aggregate demand for the good produced in region 1 is the sum of the local demand, $X_{1(1)}^{* t}$, and the demand for imports in region $0, X_{1(0)}^{* t}$. The demand for the

\footnotetext{
${ }^{4}$ Note that: $x_{n \mathbf{a} 0}^{t *} C_{n \mathbf{a}}^{t *}=x_{n \mathrm{a}}^{t *}\left(p_{\mathrm{a} 0}^{t}, p_{\mathrm{a} 1}^{t}, q_{\mathrm{a}}^{t} ; 1\right) C_{n \mathbf{a}}^{t *}=$ $x_{n \mathrm{a} 0}^{t *}\left(p_{\mathrm{a} 0}^{t}, p_{\mathrm{a} 1}^{t}, q_{\mathrm{a}}^{t} ; C_{n \mathrm{a}}^{t *}\right)$
} 
local good in region 1 is:

$$
\begin{aligned}
X_{1(1)}^{t *} & =\sum_{n \in Y} \mathrm{I}_{n}\left[\mathbf{a}^{*}: i^{*}=1\right] x_{1\left(b n \mathbf{a}^{*}\right)}^{t *} C_{b n \mathbf{a}^{*}}^{t *} \\
& +\sum_{n \in O} \mathrm{I}_{n}\left[\hat{\mathbf{a}}^{*}: r^{*}=1\right] x_{1\left(b n \hat{\mathbf{a}}^{*}\right)}^{t *} C_{b n \hat{\mathbf{a}}^{*}}^{t *}
\end{aligned}
$$

and the demand for imports of this good in region 0 is:

$$
\begin{aligned}
X_{1(0)}^{t *} & =\sum_{n \in Y} \mathrm{I}_{n}\left[\mathbf{a}^{*}: i^{*}=0\right] x_{1\left(b n \mathbf{a}^{*}\right)}^{t *} C_{b n \mathbf{a}^{*}}^{t *} \\
& +\sum_{n \in O} \mathrm{I}_{n}\left[\hat{\mathbf{a}}^{*}: r^{*}=0\right] x_{1\left(b n \hat{\mathbf{a}}^{*}\right)}^{t *} C_{b n \hat{\mathbf{a}}^{*}}^{t *}
\end{aligned}
$$

Market clearance combined with the CRS assumption yields a demand driven equilibrium output. In order to supply the demanded quantities, the firms located in regions 0 and 1 produce:

$$
\begin{aligned}
& X_{0}^{t *}=X_{0(0)}^{t *}+Q_{01}^{t} X_{0(1)}^{t *} \\
& X_{1}^{t *}=Q_{10}^{t} X_{1(0)}^{t *}+X_{1(1)}^{t *}
\end{aligned}
$$

Recall that $L_{b n \mathbf{a}}^{t *}$ denotes the labor supply of the young individual $n$, born in region $b$, conditional on a. The unconditional labor supply is the one supplied to region $j^{*}$, suggested by $\mathbf{a}^{*}$. We denote this supply by $L_{b n a^{*}}^{t *}$. Let the indicator function $\mathrm{I}_{n}\left[\mathbf{a}^{*}: j^{*}=0\right]$ attain the value 1 if the young individual $n$ is choosing an alternative $\mathbf{a}^{*}$ under which she supplies labor in region 0 . The labor market clearing condition for region 0 is:

$$
\sum_{n \in Y} \mathrm{I}_{n}\left[\mathbf{a}^{*}: j^{*}=0\right] L_{b n \mathbf{a}^{*}}^{t *}=X_{0}^{t *}\left\{\frac{R^{t}}{w_{0}^{t}} \frac{\beta}{\alpha}\right\}^{\alpha}
$$

And for region 1:

$$
\sum_{n \in Y} \mathrm{I}_{n}\left[\mathbf{a}^{*}: j^{*}=1\right] L_{b n \mathbf{a}^{*}}^{t *}=X_{1}^{t *}\left\{\frac{R^{t}}{w_{1}^{t}} \frac{\beta}{\alpha}\right\}^{\alpha}
$$

The capital market clearing condition:

$$
\sum_{n \in O} K_{n}^{t}=X_{0}^{t *}\left\{\frac{w_{0}^{t}}{R^{t}} \frac{\alpha}{\beta}\right\}^{\beta}+X_{1}^{t *}\left\{\frac{w_{1}^{t}}{R^{t}} \frac{\alpha}{\beta}\right\}^{\beta}+K_{\mathrm{G}}^{t}
$$

The equilibrium volume of interregional trade between locations 0 and 1 is:

$$
\hat{X}_{01}^{t}=X_{0(1)}^{* t}+X_{1(0)}^{* t}
$$

The regional land market clearing condition for zone 0 is:

$$
\begin{aligned}
\sum_{n \in H_{0}} \bar{l}_{n} & =\sum_{n \in Y} I_{n}\left[\mathbf{a}^{*}: i^{*}=0\right] l_{b n \mathbf{a}^{*}}^{t *} C_{b n \mathbf{a}^{*}}^{t *} \\
& +\sum_{n \in O} I_{n}\left[\hat{\mathbf{a}}^{*}: r^{*}=0\right] l_{b n \hat{\mathbf{a}}^{*}}^{t *} C_{b n \hat{\mathbf{a}}^{*}}^{t *}
\end{aligned}
$$

Where $H_{0}$ denotes the set of agents that own land in region 0 , with land endowment denoted by $\bar{l}_{n}$. The land demands $l_{b n \mathbf{a}^{*}}^{t *}\left(p_{0 \mathrm{a}^{*}}^{t}, p_{1 \mathbf{a}^{*}}^{t}, q_{\mathbf{a}^{*}}^{t} ; C_{b n \mathbf{a}^{*}}^{t *}\right)$ and $l_{b n \hat{\mathbf{a}}^{*}}^{t *}\left(p_{0 \hat{\mathbf{a}}^{*}}^{t}, p_{1 \hat{\mathbf{a}}^{*}}^{t}, q_{\hat{\mathbf{a}}^{*}}^{t} ; C_{b n \hat{\mathbf{a}}^{*}}^{t *}\right)$ are Marshalian since $C_{b n \mathbf{a}^{*}}^{t *}$ and $C_{b n \hat{\mathbf{a}}^{*}}^{t *}$ are the maximum subutilities a young(old) individual can achieve under the choice of $\mathbf{a}^{*}\left(\hat{\mathbf{a}}^{*}\right)$.

The clearing condition for zone 1 :

$$
\begin{aligned}
\sum_{n \in H_{1}} \bar{l}_{n} & =\sum_{n \in Y} I_{n}\left[\mathbf{a}^{*}: i^{*}=1\right] l_{b n \mathbf{a}^{*}}^{t *} C_{b n \mathbf{a}^{*}}^{t *} \\
& +\sum_{n \in O} I_{n}\left[\hat{\mathbf{a}}^{*}: r^{*}=1\right] l_{b n \hat{\mathbf{a}}^{*}}^{t *} C_{b n \hat{\mathbf{a}}^{*}}^{t *}
\end{aligned}
$$

Since the zero profit conditions coincide with profit maximization conditions, from (26) we get:

$$
p_{1}^{t}=\left(\frac{w_{1}^{t}}{w_{0}^{t}}\right)^{\beta}
$$

Note that we have implicitly adopted the standard price normalization of an equilibrium model by setting the good produced in region 0 as the nummeraire good and its price equal to one. Finally, under the full capital depreciation rate, the capital accumulation rule becomes:

$$
\begin{array}{r}
K^{t+1}=\sum_{n \in Y}\left\{L_{b n \mathbf{a}^{*}}^{t *}\left(1+d_{b n \mathbf{a}^{*}}\right) w_{\mathbf{a}^{*}}^{t}\left(1-z^{t}\right)\right. \\
-P_{\mathbf{a}^{*}}^{t} C_{b n \mathbf{a}^{*}}^{t *}+M_{n}^{t}-\psi_{\mathbf{a}^{*}}-F_{\bar{i} \mathbf{a}^{*}}
\end{array}
$$

\footnotetext{
${ }^{5}$ With full depreciation, no capital survives until the next time period (generation). There is no public capital left either.
} 
which means that the capital supply in period $t+1$ consists of the current young generation's savings. The next sections present the methodology of the simulation experiments, plot the results and discuss them.

\section{Simulation Experiments}

\subsection{Simulation Set-up and the F.R.O.G. Solution Algorithm}

All experiments in this paper simulate the adjustment process between two steady states with different level of infrastructure. The shock is an unanticipated, permanent increase in public capital; that is, an upgrade in the transport link between the two regions. We define the steady state equilibrium as a situation in which capital, output and consumption grow at a constant rate, in this case zero. The transition to the steady state depends on the assumptions on the formation of the agents' expectations. We assume that these expectations are myopic; that is, individuals extrapolate current prices, wages and rents into the future. More specifically:

$$
\begin{aligned}
& \left(P_{0}^{\mathrm{e}(t+1)}, P_{1}^{\mathrm{e}(t+1)}\right)=\left(P_{0}^{t}, P_{1}^{t}\right) \\
& R^{\mathrm{e}(t+1)}=R^{t} \\
& M_{n}^{\mathrm{e} t+1}=M_{n}^{t}
\end{aligned}
$$

Where the beliefs in (52) and (53) are collective while those in (54) are individual specific. These expectations do not need to be correct, even on average, as it is the case for rational expectations; however, they turn out to be correct in the steady state, where all real prices and per capita variables stabilize. Michel and de la Croix (2000) show that, in an OLG model, the steady states under myopic and perfect foresight are essentially the same.

In order to simulate a transition process in any of our experiments, two artificial populations of one hundred individuals are generated, one for each zone. Population growth is ruled out by ensuring that the two generations have a stable number of members. Each household consists of a sole individual in order to circumvent complications that arise in pair decision making ${ }^{6}$. All individuals born at time $t$ inherit a land bequest from an agent who, at that time becomes two generations old and, leaves the model. An arbitrary individual's skill deviation, $d_{b n j}$ which is the main

\footnotetext{
${ }^{6}$ For a simulation model with simulated couples see McArthur et al. (2010)
}

source of household heterogeneity, is drawn from a Johnson $S B$ distribution. That is, if the random variable $\tilde{d}$ follows the Normal distribution $N(\mu, \sigma)$ then the transformation:

$$
d_{b n j}=e_{b j}^{0}+e_{b j}^{1}\left\{\frac{\exp \left(\tilde{d}_{n}\right)}{1+\exp \left(\tilde{d}_{n}\right)}\right\}
$$

is a Johnson-SB random variable, bounded on the $\left(e_{b j}^{0}, e_{b j}^{0}+\right.$ $\left.e_{b j}^{1}\right)$ interval. That is, the individual's innate ability, $\frac{\exp \left(\tilde{d}_{n}\right)}{1+\exp \left(\tilde{d}_{n}\right)}$ is bounded on the $(0,1)$ interval. Note that this term is independent of the individual's region of origin, $b$, and the region of labor supply, $j$. It reflects the inherent part of ability, which is independent of education, experience or working place.

The bounding parameters $e_{b j}^{0}$ and $e_{b j}^{1}$ transform this unobserved ability into a skill shock that the individual $n$, raised in region $b$ is endowed with when working in region $j$; thus, each individual carries one skill shock term $d_{b n j}$ for each region of production. The rationale behind this is the stylized fact that the same level of skill is evaluated differently in different regions (industries). Furthermore, the moments of the distribution of skill supplied to a region (industry) are different across groups of workers that originate from different regions. Capturing this regularities, $d_{b n j}$ may be viewed as a matching term.

The errors in the utility functions in 2.1.1 are drawn from the EV type I distribution with scale parameter $\chi_{0}$ and location parameter $\chi_{1}$. Capital bequests and land trade is assumed away, in order to rule out altruistic preferences, something that would distort the OLG structure towards an infinite horizon model.

To invoke the FROG solution algorithm we use an initial guess of the price vector $v_{0}=\left(q_{0}^{t}, q_{1}^{t}, w_{0}^{t}, w_{1}^{t}, p_{1}^{t}, R^{t}, z^{t}\right)$, together with the parameter vectors: $\left(\varphi_{0}, \varphi_{1}, \theta, \zeta, \eta, \chi_{0}, \chi_{1}\right)$ for preferences in the middle and lower level, the parameters for skill heterogeneity, $(\alpha, \beta)$ for private production technology, $(\xi, \omega, \varsigma)$ for the effects of public capital on transport costs and a discount rate $\delta$. We also guess an initial level of public capital $K_{\mathrm{G}}^{0}$. From these values, commuting time between zone 0 and $1, v_{01}^{t}$, and the iceberg fraction reciprocal, $Q_{10}^{t}$ can be computed from (32) and (36).

Each iteration consists of the following steps. First, the consumer optimization problem is solved from the bottom level to the upper level. For an arbitrary individual, the regional price index, $P_{\mathbf{a}}^{t}$, is computed from (21). This price index and its myopic future expectation, $P_{\mathbf{a}}^{\mathrm{e}(t+1)}$, are then used 
to compute an alternative specific consumption-leisure stream $C_{b n \mathbf{a}}^{t *}, C_{b n \mathbf{a}}^{t+1 *}$ for each young individual and the consumption $C_{b n \hat{\mathbf{a}}}^{t *}$ for each old individual. To attain the consumption stream, we insert $P_{\mathrm{a}}^{t}$ and $P_{\mathrm{a}}^{\mathrm{e}(t+1)}$ in the intertemporal budget constraint in (5) and solve the system of first order conditions in the consumer's maximization problem.

For each individual, the computed $C_{b n \mathbf{a}}^{t *}$ and $C_{b n \hat{\mathbf{a}}}^{t *}$ are inserted into (18)-(20) to get the associated divided demands for the manufactured goods and land. Finally, the utility of each alternative can be computed from the upper level choice, and more explicitly from (12) for the young and (15) for the old individual. A simulated choice is generated when the process is completed for every alternative of the choice set.

The set of simulated choices $\mathscr{C}$ of alternatives contains a simulated choice $\mathbf{a}^{*}=\mathbf{a}^{*}(b, n, t)$ for each young individual and one choice $\hat{\mathbf{a}}^{*}=\hat{\mathbf{a}}^{*}(b, n, t)$ for each old individual. Using these choices, we compute the aggregate demands for the manufactured goods and land. These demands are accommodated by the regional representative firms in the equilibrium, therefore the simulated factor demands can be computed directly from equations (24) and (23) by adjusting the exported quantities for the melting costs. If congestion effects in trade are assumed to exist, the reciprocal of the iceberg fraction can be computed using (47). It is then straightforward to get the simulated excess demand vector for land and labor in the two locations and for capital in the common market. The set of simulated choices $\mathscr{C}$ produces a simulated government revenue, through commuting, relocation and labor supply choices of the population. A simulated budget surplus is then computed from (37).

The solution to the system of simulated excess demand equations for land, labor capital and governmental surplus, $\mathbf{f}\left(\mathbf{w}, \mathbf{q}, p_{1}, R, z\right)$ is approximated using the Newton method for multivariate equations (Judd 1998), combined with a line search method. The necessity of the incorporated line search method lies on the fact that the above system is highly non-linear; without restricting the Newton correction in each iteration, some prices may attain negative values between iterations, something that contradicts the standard restriction of non-negative prices for all private goods. The simulation process of excess demands and supplies is performed as many times as necessary, in order to obtain a numerical Jacobian matrix $J\left(\mathbf{w}, \mathbf{q}, p_{1}, R, z\right)$ for the iteration-specific price vector: $\mathbf{v}^{i}=\left(\mathbf{w}^{i}, \mathbf{q}^{i}, p_{1}^{i}, R^{i}, z^{i}\right)$. The hybrid Newton iteration scheme is:

$$
\mathbf{v}^{i+1}=\mathbf{v}^{i}-\varepsilon^{*} J\left(\mathbf{v}^{i}\right)^{-1} \mathbf{f}\left(\mathbf{v}^{i}\right)
$$

with $\varepsilon$ denoting a scalar in a prespecified interval between zero and a real number, usually smaller than one. For each $\varepsilon$ a new price vector is attained, and the one for which the Euclidean norm $\left\|f\left(\mathbf{v}^{i+1}\right)\right\|$ is minimized, $\varepsilon^{*}$, is used for the next iteration. The entire process is repeated until all equations are sufficiently close to zero; this is dictated by the convergence criterion $\left\|f\left(\mathbf{v}^{i+1}\right)\right\| \leq u$. Finally the process is repeated for each time period, until the convergence to myopic steady state equilibrium has been obtained.

Since population growth has been assumed away, in the myopic steady state capital intensity becomes constant. Simultaneously, all prices, wages, rents, the interest rate and the labor tax are stabilized to their steady state values. Note that this is possible only when consumers are not heterogenous. In simulation experiments with skill heterogeneity, a myopic pseudosteady state is assumed and obtained when the factor use path is stable enough, to ensure that the sufficiently small fluctuations are produced by skill heterogeneity and not by a remaining adjustment process. In this case, there is a tradeoff between implied sufficiency and computational tractability. Figure 1 summarizes the FROG solution algorithm.

\subsection{Experiments}

The simulation experiments are grouped into two main categories. The first group contains 'textbook' style models in which all parameters that control skill heterogeneity are set to 0 . These models are expected to produce zero migration and interregional commuting, simply because their monetary and time costs eliminate any incentive for the above actions. Therefore, agents continue to live and work in the zone they were born, independent on how strong their preference for their birth place, captured by $\vartheta$ in (9), is. Despite this, they keep on consuming the manufactured good that is imported, by the assumption of necessity we implicitly made in the utility specification in section 2.1.3. Therefore the upgrade of the transport system has two effects upon them. It reduces the cost of trade and therefore imports become cheaper; the regional price index falls and consumption is expected to increase. If the infrastructure set-up was cost free, no further investigation would be necessary. The set-up cost, however, is collected by imposing a tax on labor income. The distortionary effects of this tax have an impact on the equilibrium use of labor. It is shown that, in the case of high set-up costs relative to transport cost gains (that is beyond a critical level of the parameters $A$ and $\omega$ ) the infrastructure upgrade might 


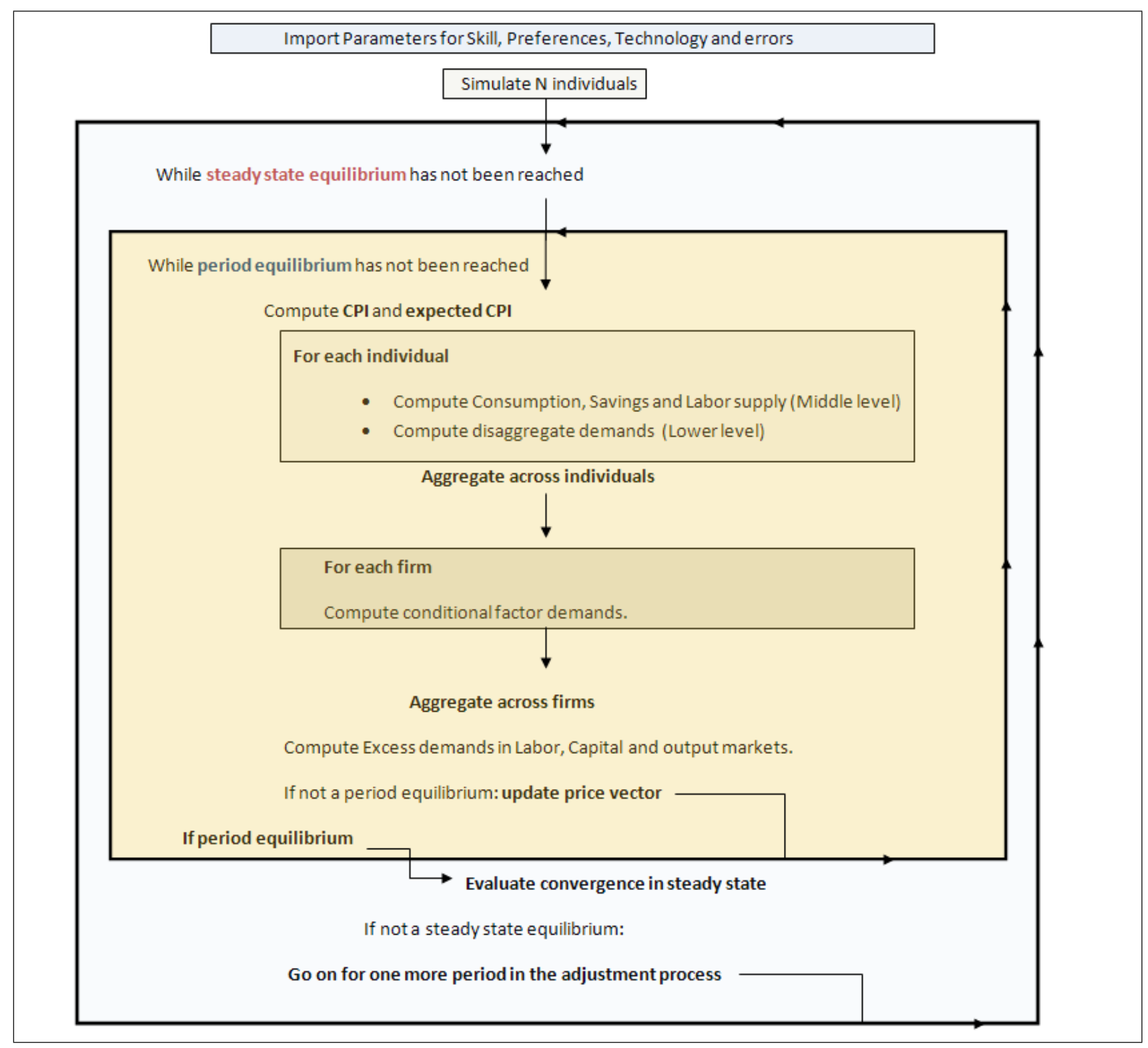

Figure 1: The FROG solution algorithm

lead to a steady state equilibrium with lower output per capita and lower use of labor.

$$
\begin{aligned}
& \text { i) } e_{(00)}^{0}=e_{(00)}^{1}=e_{(11)}^{0}=e_{(11)}^{1}=0 \\
& \text { ii) } e_{(01)}^{0}=e_{(10)}^{0} \text { and } e_{(01)}^{1}=e_{(10)}^{1}
\end{aligned}
$$

The second set of models contains set-ups with labor skill heterogeneity. In all settings, we assume that heterogeneity is i) absent in the home industry and ii) symmetric with respect to the foreign sectors. According to (55), the above assumptions translate to:

We set $e_{(01)}^{0}=-x$ and $e_{(01)}^{1}=2 x$ in order to postulate a foreign sector skill deviation distribution on the interval $[-x, x]$. We then perform similar simulation experiments as 
in the first group of models, but with a major difference. We also allow the origin specific constant to take values different than zero. We expect that this constant proves to be an important control factor in the decisions of commuting and relocation for two reasons. First, it captures all the effects of unobserved factors that correlate with the area of origin: an already formed social setting and the ability of daily-based communication with a social circle are important factors that certainly affect the decision of interregional migration, but have a rather weak effect when it comes to interregional commuting. These effects add a non-pecuniary cost on the existing pecuniary frictions. Secondly, this constant increases the generalized cost of migration compared to that of commuting. In a two period OLG setting, it is highly unlikely that a fixed relocation cost will be dominant compared to an annual cost of interregional commuting. Without some non-pecuniary frictions added to relocation it is almost impossible to generate a positive commuting rate in the state as a result of skill heterogeneity.

\subsubsection{Experiments with homogenous labor}

Figure 2 highlights the first group of experiments that are also tabulated in table 1 . The transition path to the first steady state is of minor importance and therefore omitted in all graphs. The transition to the new steady state is characterized by an initial boom in consumption; this is due to the fact that regional price indexes fall in both regions. However the expectations over the labor tax are myopic; consumers do not foresee the necessary tax increase in order to finance the public capital. Therefore, after the first period in the adjustment process, consumption is corrected for the new information revealed to agents.

The interpretation of the results is rather straightforward. Without labor heterogeneity, for any given set of model parameters, there exists a threshold in the cost elasticity, such that the reduction in interregional trade costs exceeds the output foregone in order to set up and perpetuate the transport link in each generation. This is highlighted in figure 3. Of course, the elasticity threshold level is determined from the parameter values of table 4. We approximate this threshold level by simulating four different adjustment processes; in each of them all parameters but the elasticity of transport costs with respect to public capital remain fixed. We allow the elasticity to take four different values, namely $-2.25,-0.67,-0.21$, and -0.1031 . In each simulation scenario we assume that the shock that pushes the system away from its initial steady state is a capital investment on the link. More specifically, the initial capital on the link is set to 0.3 and is increased to 0.5 . The elasticities are derived directly from transport technologies in (32) under four different assumptions about the decreased transport costs. Note that the initial iceberg constant is set to 2, i.e., only half of the exported output reaches its destination. The adjustment processes yield four different steady state outputs. We interpolate by fitting a trend to these points (Figure 3) to obtain some useful conclusions. The increment in public capital leads to increased steady state consumption only for an elasticity of transport costs with respect to public capital which is high enough, in this case above 0.45 . Figures 4 and 5 plot the evolution of aggregate consumption and savings in the adjustment paths.

A set of other intuitive results is worth mentioning, too. Because of symmetric technologies, preferences, and population sizes in the two regions, all wage, rent, and price disparities are equal to zero both throughout the entire adjustment process and in the final steady state. Furthermore the intergenerational interest rate is slightly different between the two steady states since government increases its demand to perpetuate a link that costs more to each generation after the shock. This result is fortified by the fact that the regional prices of consumption fall when transport costs sink. Equilibrium commuting and migration is completely determined by the initial set of hypotheses, and is essentially zero.

\subsubsection{Experiments with heterogenous labor skill}

We now proceed to the second set of experiments. We adopt as base model the one which produced the highest growth in section 3.2.1 and compare it to three models with different degree of labor skill heterogeneity, and with the home-effect parameter $\vartheta$ increased from 0 to 0.5 . The parameters we have used to generate the skill distribution in each zone are given in the first four columns of Table 3. Figure 6 shows a simulated version of the Johnson-SB skill probability density functions used in Model 1, 2 and 3, with 100000 draws. Figure 7 shows the corresponding cumulative density functions.

It is important to recognize that, since the allocation of skill at any point in time is no more determined by a degenerate distribution, the output and the use of productive factors both in the adjustment process and in the final pseudo-steady state are random variables that follow an unknown distribution. For this reason, the simulation process has to be repeated to generate a sample of adjustment processes, taking into account the trade-off between sample size and computational time. We repeat the simulation experiment $15-20$ times as Table 3 suggests. An 'average' adjustment process for the each of the three models is given in Figure 8.

Under the assumption that output values for the same generation across different simulation experiments constitute an 


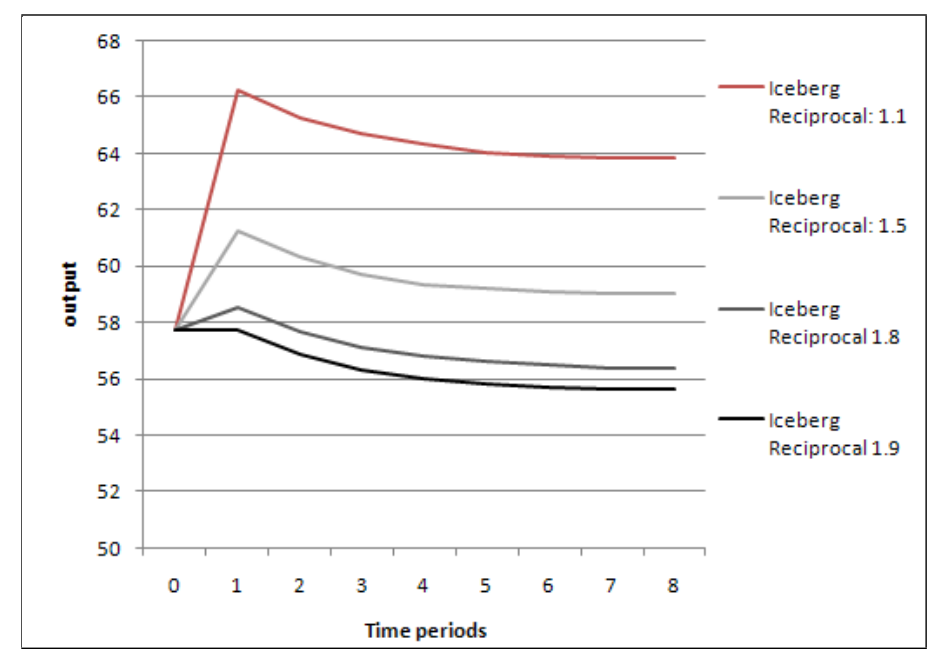

Figure 2: Myopic steady states and adjustment processes for different cost elasticities

Table 1: Simulation experiments without labor skill heterogeneity

\begin{tabular}{ccccc}
\hline $\mathrm{A}$ & $\omega$ & Elasticity & Initial Output: $\mathrm{Y}_{0}$ & Final Output: $\mathrm{Y}_{1}$ \\
\hline 0.004 & -4.508 & -2.250 & 57.734 & 63.810 \\
0.195 & -1.357 & -0.670 & 57.734 & 59.042 \\
0.591 & -0.437 & -0.210 & 57.734 & 56.397 \\
0.780 & -0.206 & -0.103 & 57.734 & 55.636
\end{tabular}

Table 2: Consumption and savings in the initial and final steady state

\begin{tabular}{ccccccc}
\hline Elasticity & $\mathrm{C}_{0}$ & $\mathrm{C}_{1}$ & $\mathrm{~S}_{0}$ & $\mathrm{~S}_{1}$ & \% change in C & \% change in S \\
\hline-2.25 & 39.56 & 46.96 & 18.16 & 16.83 & 18.710 & -7.307 \\
-0.67 & 39.56 & 42.19 & 18.16 & 16.84 & 6.642 & -7.265 \\
-0.21 & 39.56 & 39.55 & 18.16 & 16.84 & -0.025 & -7.305 \\
-0.1 & 39.56 & 38.80 & 18.16 & 16.83 & -1.924 & -7.357
\end{tabular}

Table 3: Simulation experiments with labor skill heterogeneity and fixed transport cost elasticity

\begin{tabular}{ccccccccc}
\hline Model & $e_{(01)}^{0}$ & $e_{(10)}^{0}$ & $\varrho_{(01)}^{1}$ & $\varrho_{(10)}^{1}$ & Rounds & $Y_{0}$ & Mean $Y_{1}$ & Growth \\
\hline Base & 0.0 & 0.0 & 0.0 & 0.0 & 1 & 57,734 & 63,809 & 0,105 \\
Model 1 & -0.3 & -0.3 & 0.6 & 0.6 & 20 & 57,698 & 63,529 & 0,101 \\
Model 2 & -0.4 & -0.4 & 0.8 & 0.8 & 15 & 57,421 & 65,606 & 0,143 \\
Model 3 & -0.55 & -0.55 & 1.1 & 1.1 & 20 & 57,709 & 67,607 & 0,172 \\
& & & & & & & & \\
\hline
\end{tabular}




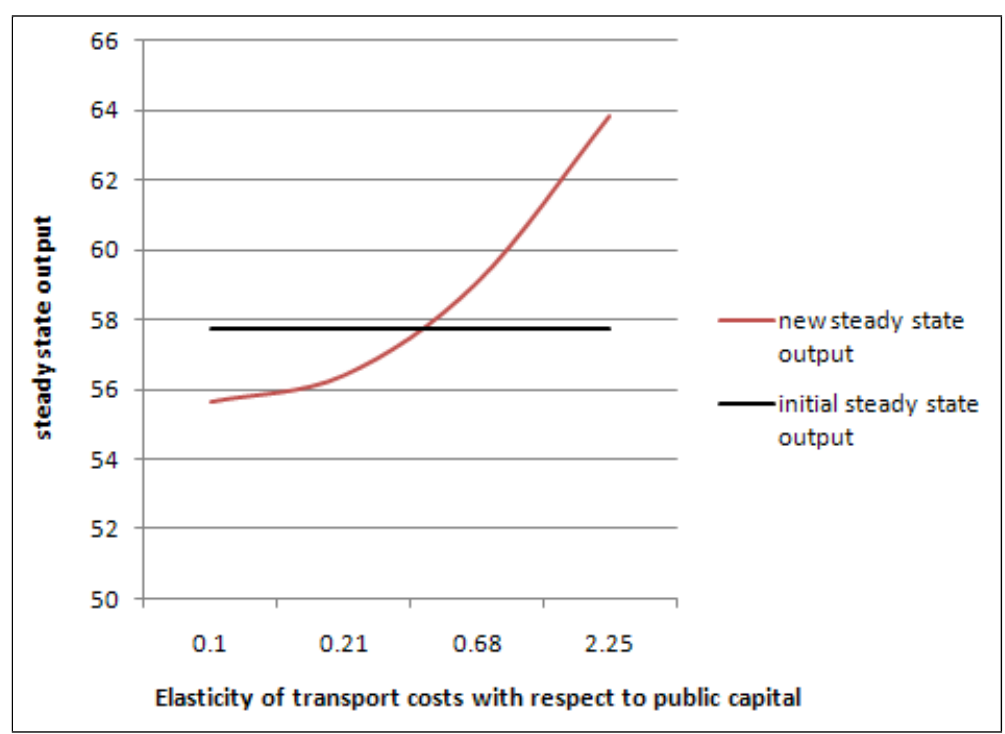

Figure 3: Post-shock steady state output against transport cost elasticity without labor heterogeneity

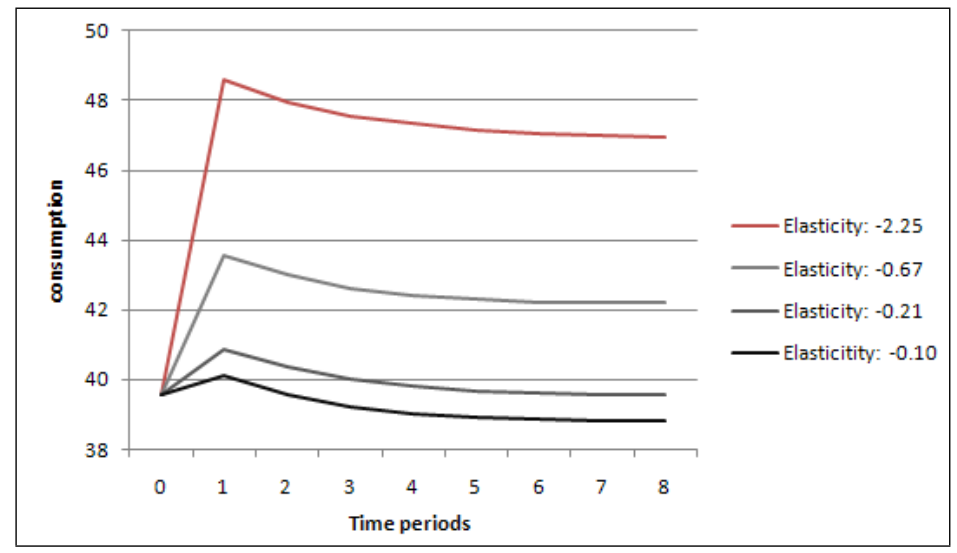

Figure 4: Consumption adjustment under different transport cost elasticities

i.i.d. sample we construct $95 \%$ confidence intervals both from the finite properties of a random sample (solid grey lines), using the $t$-student distribution, and from large sample theory (dashed lines), using the normal distribution. These confidence intervals for the output level in each period are plotted together with the output adjustment process of the base model in Figures 9, 10, and 12, and provide a concise measure of the stability of the output adjustment across different simulation rounds.

From Figure 9 it can be seen that the difference in steady state output level between the cases of homogenous and slightly heterogenous labor force is not statistically significant. This is due to the fact that the low variance in the skill distribution chokes every possibility of commuting and the unob- served place heterogeneity captured by an origin specific constant chokes the possibility of migration. Under these assumptions, the gains from the public infrastructure shock are essentially the same as in the base model, i.e., due to output trade effects only.

The picture changes in Model 2, however. Here, we have assumed a medium degree of skill heterogeneity. The infrastructure shock generates positive rates of commuting throughout the adjustment process and in the new steady state. Figure 10 shows that there are statistically significant labor matching effects in the total output which fortify the existing trade effects. With lower frictions, a given wage rate is more probable to compensate the commuting workers for the loss of time and commuting expenses. Subsequently, 


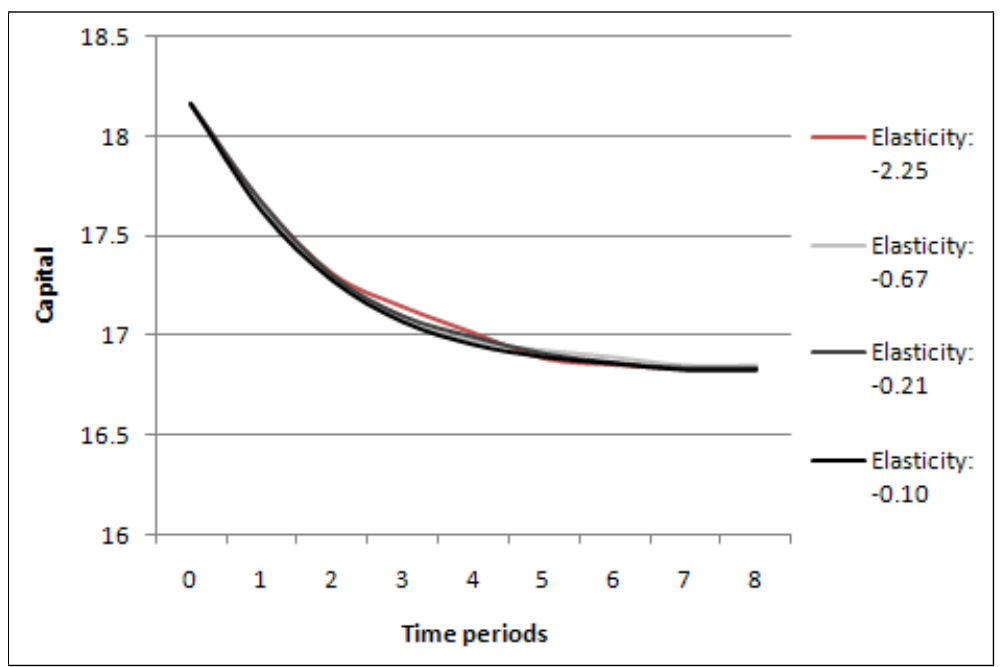

Figure 5: Savings adjustment under different transport cost elasticities

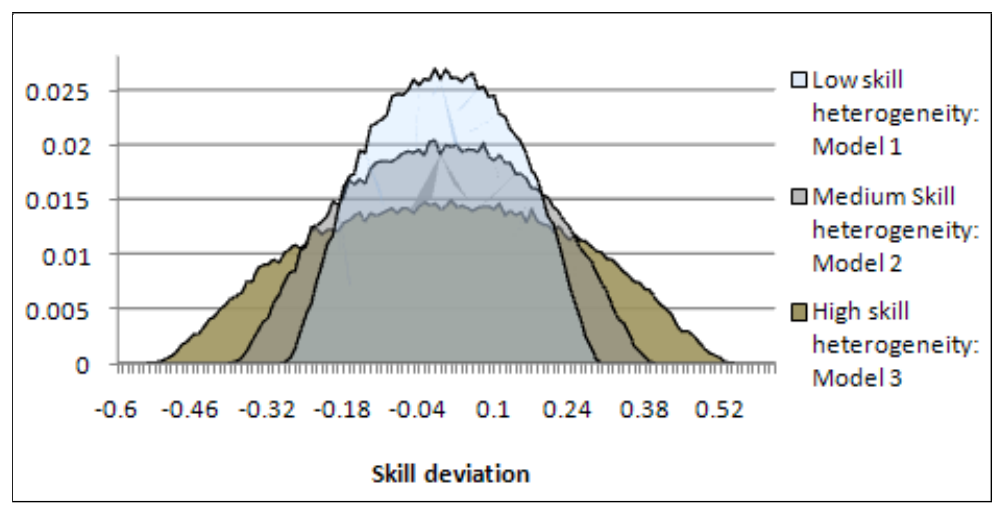

Figure 6: Simulated skill pdf for Models 1, 2 and 3 with 100000 draws.

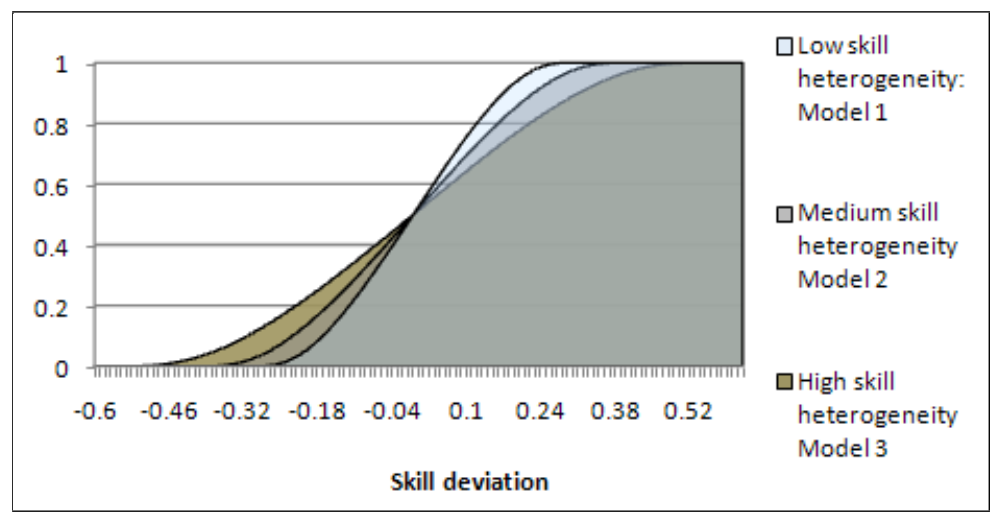

Figure 7: Simulated skill cdf for Models 1, 2 and 3 with 100000 draws.

some of the workers that can be more productive when supplying labor in the other region will now accept to do so by commuting. The effect can be regarded as an expansion of the production possibilities frontier; there is a higher total 


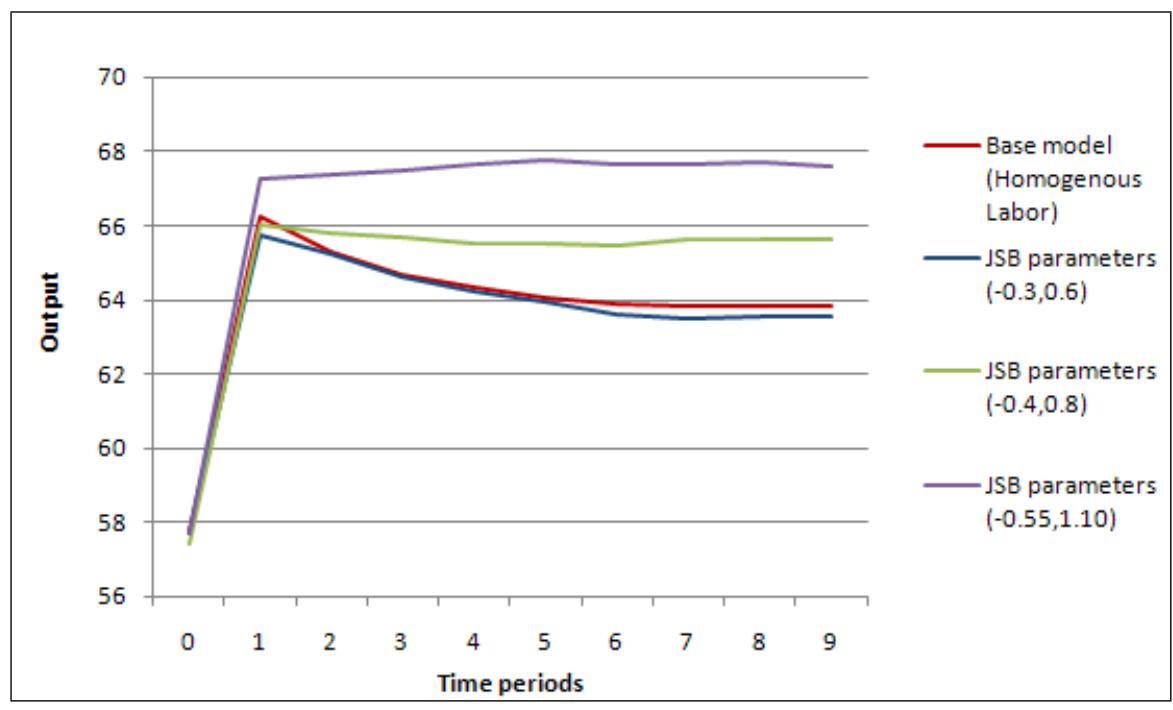

Figure 8: Adjustment processes with various levels of skill heterogeneity

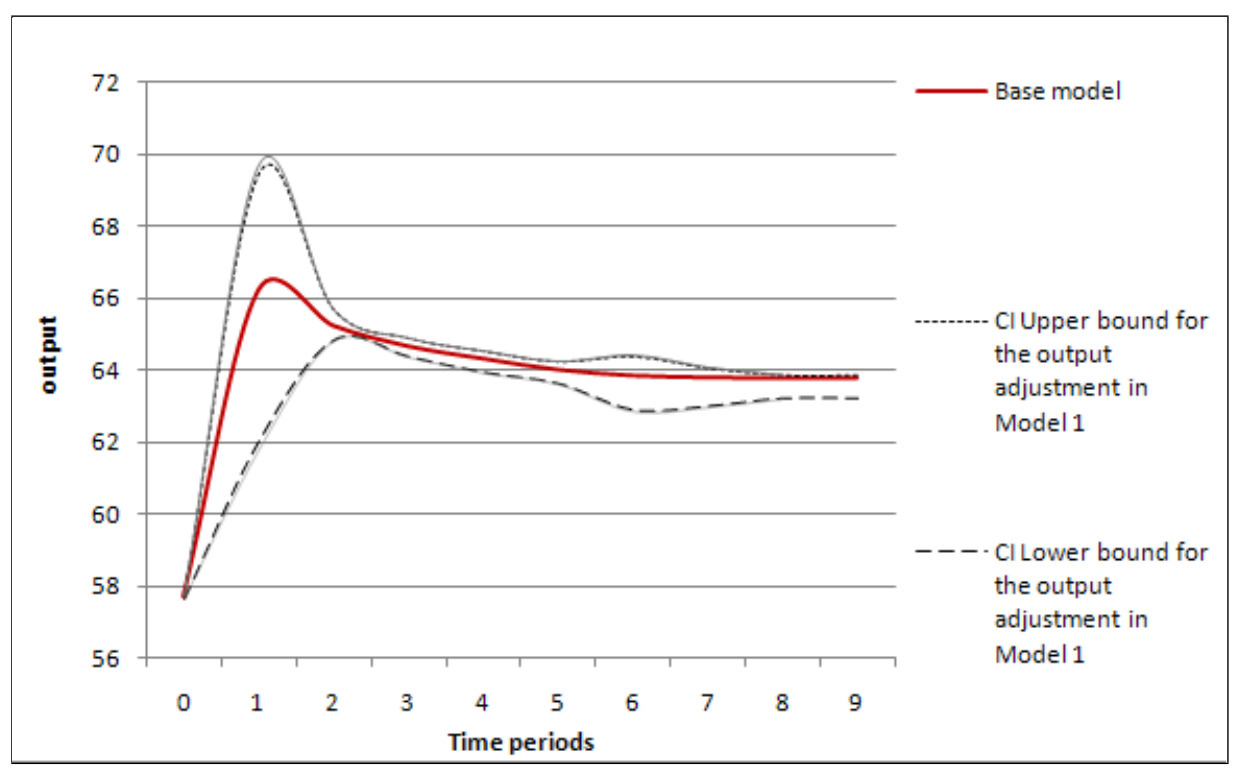

Figure 9: Original Adjustment process versus the 95\% confidence interval bounds of the adjustment process in Model 1.

amount of skill endowment in the economy. The increased labor market efficiency will drive the economy to a steady state with higher output and consumption compared to those of the base model. The commuting pattern generated in Model 2 is plotted in Figure 11, where it is shown that our parametric input gives rise to a commuting rate of approximately $4 \%$.

Finally, Model 3 investigates the scenario of an even higher degree of skill heterogeneity in the population. The result is clearer in this case. The additional, matching effect can cause an additional growth of almost $7 \%$ (Figure 12). The percentage of the population which commutes in this case, is also higher, as Figure 13 suggests.

\section{Synopsis and future challenges}

We have presented a simulated version of a heterogenous agent, spatial OLG model in two regions. The source of heterogeneity stems from a one-dimensional skill deviation from the population mean. In each simulation experiment, we sim- 


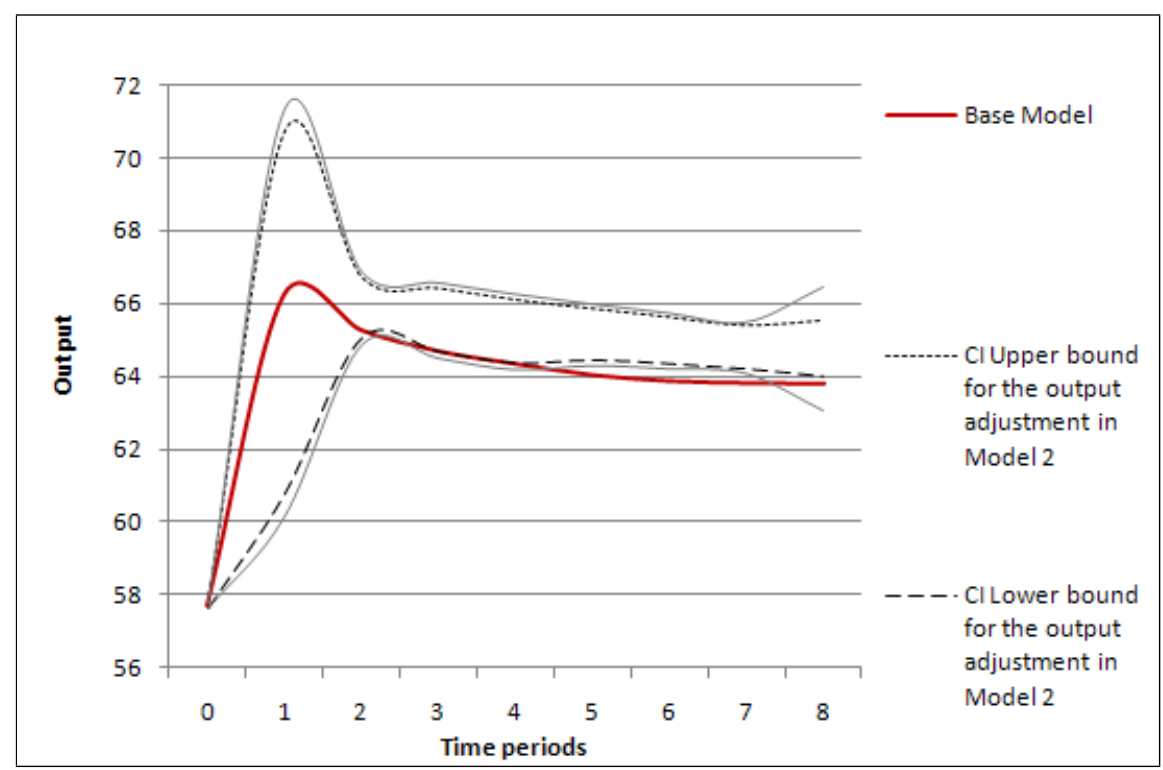

Figure 10: Original Adjustment process versus the 95\% confidence interval bounds of the adjustment process in Model 2.

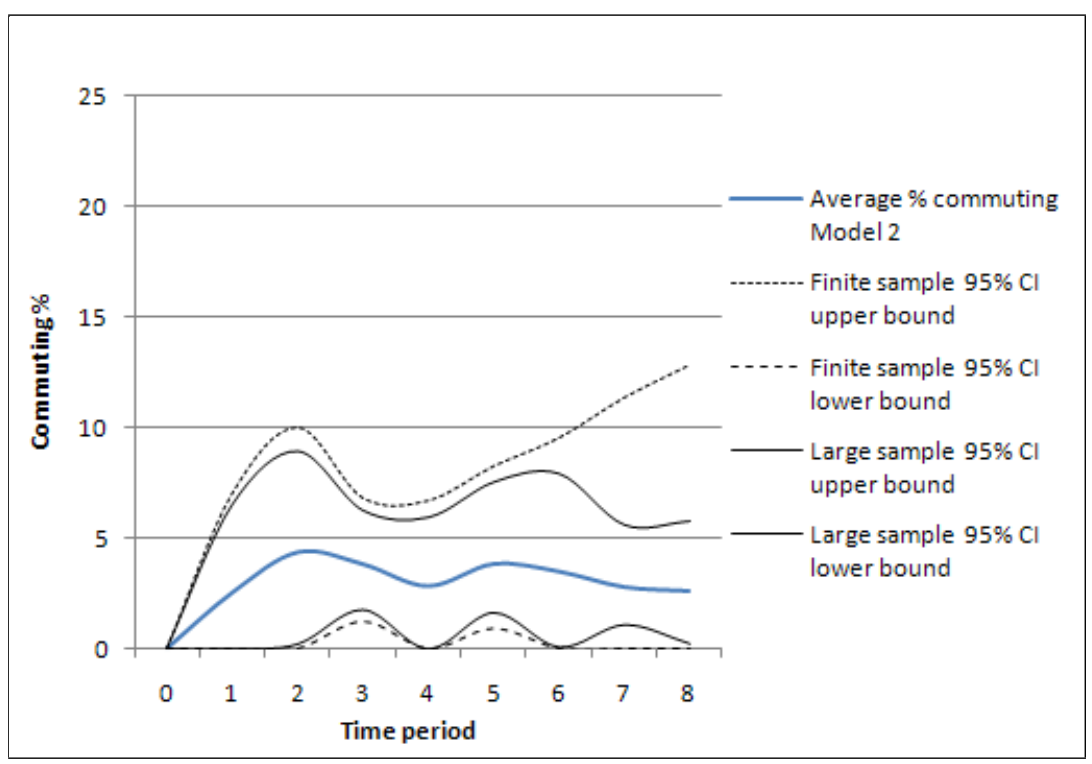

Figure 11: Commuter percentage of the population with its 95\% finite sample and asymptotic confidence intervals in Model 2.

ulated two steady state equilibria: one before and one after a shock in the level of public infrastructure, in our case an update in a transport link between the two zones. We have been able to divide the output change into two main components. The first originates from trade effects; since transport costs are decreased, regional price indices fall and demands for the two commodities increase. If the cost fall is sufficient to outweigh the output foregone in public investment, the economy is driven to a new steady state with higher per capita consumption.
The second effect, which is highlighted in this paper, stems from the efficiency in the labor market; the higher the degree of heterogeneity in skill, with which the labor force is endowed towards the interregional production processes, the higher the number of workers that could potentially supply this skill in the non-domestic sector. For any given set of frictions (relocation costs, commuting costs and time, unobserved factors that correlate with the place of origin etc.), there exists one level of skill heterogeneity that generates interregional migra- 


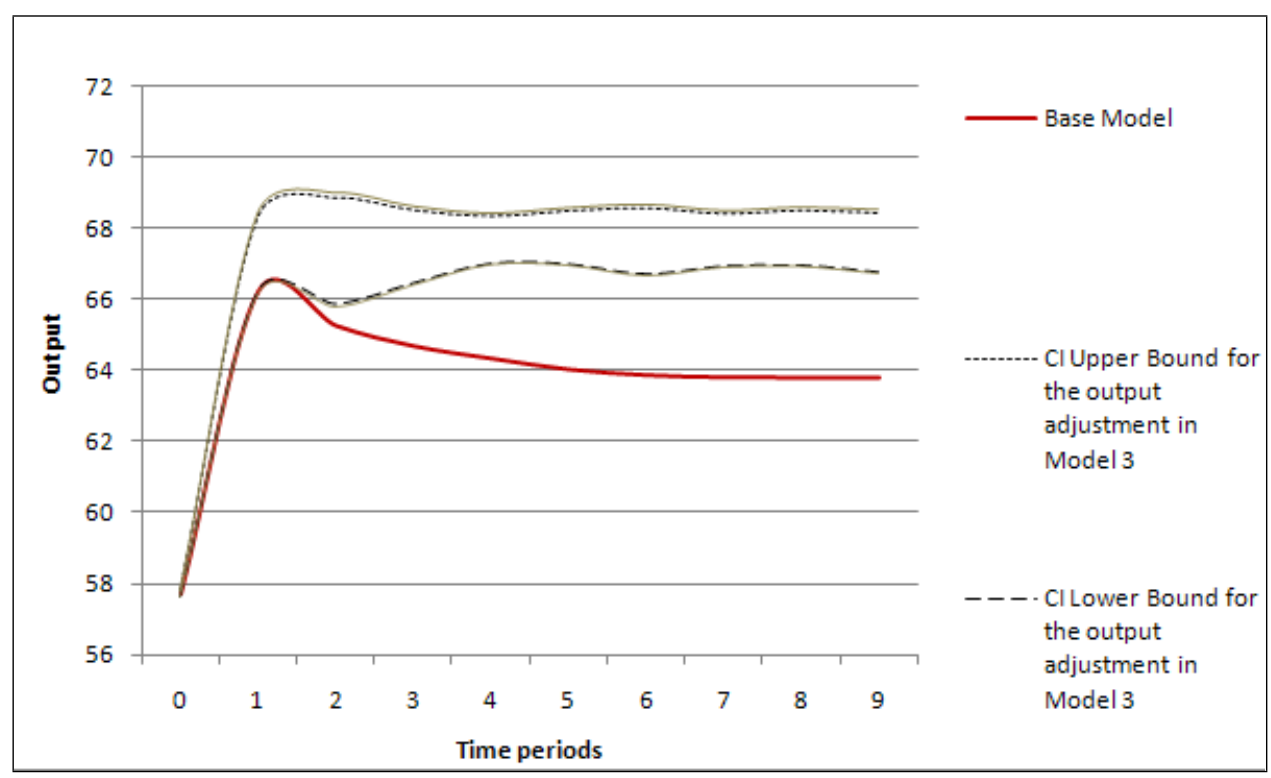

Figure 12: Base Adjustment process versus the 95\% confidence interval bounds of the adjustment process in Model 3.

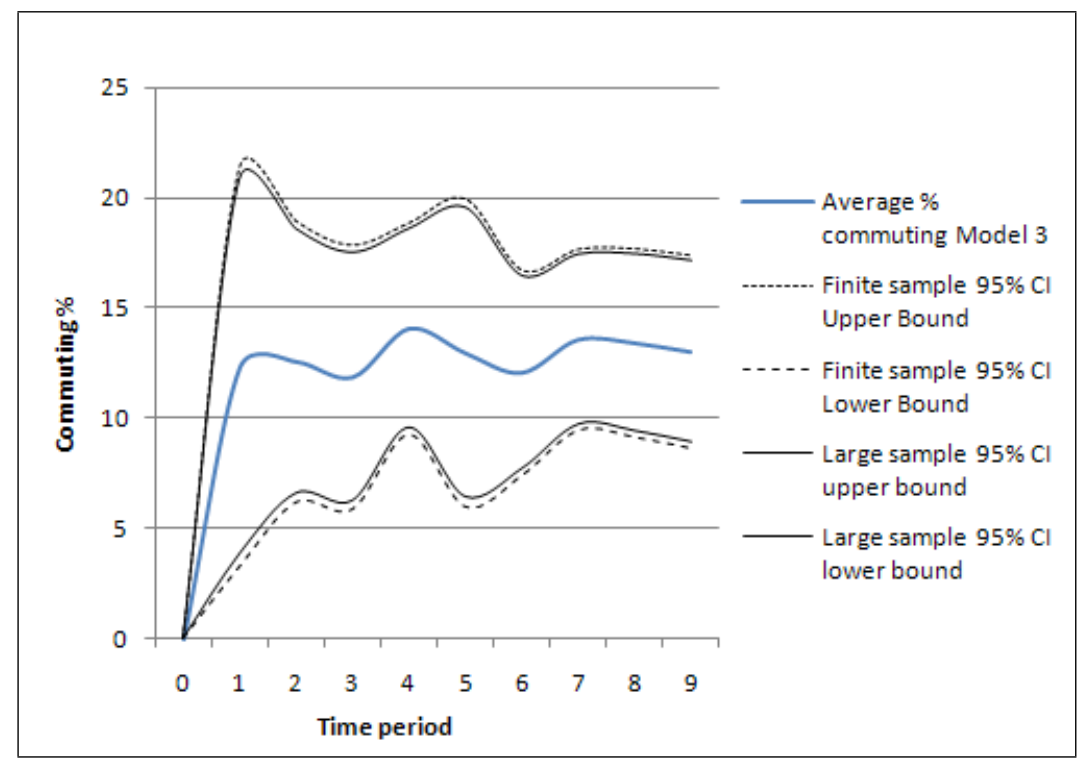

Figure 13: Commuter percentage of the population with its 95\% finite sample and asymptotic confidence intervals in Model 3.

tion and/or commuting. The lower the frictions, the lower this threshold is and the higher the gains from matching.

The authors plan to further develop the platform of this paper in the future, and estimate the model's parameters, using the region of Öresund as empirical reference. In this area, a significant socioeconomic experiment takes place since July 2000, with the opening of a bridge which connects the Swedish city Malmö with the Danish capital, Copenhagen, al- lowing the labor, land and output markets of these areas to interact in an interesting way.

Having estimates of the models' parameters will give some insight on the portion of growth in regional product observed after the introduction of the bridge which has been realized through changes in the labor market. As pointed out in the introduction, this portion could have been realized with some alternative policy, for instance, through employee training 
programs. Therefore, a future version of the model can be used as an auxiliary device for policymaking of such type.

Parallel to that, the strong set of model's assumptions leaves space for future improvements. However, assumptions of such strength are rather the norm than the exception when the scope is to get some insight in a complex economic model. This holds especially for the assumptions of two regions, no population growth, and the absence of capital bequests and land trades.

Improving transport infrastructure in this highly symmetrical model typically leads to symmetrical results for the two regions. The output will either increase, or decrease in both regions. It is expected that the introduction of more regions into the model would break such symmetries; there may be some regions that benefit while others lose. Intuitively, trade patterns are dependent on the level of infrastructure provision, and trade may be shifted towards the region(s) which become more accessible. Thus, the trade effects stemming from an increase in local infrastructure in a multiregional setting may be negative for the relatively less accessible regions, as their export base is reduced. The authors consider the introduction of more regions as one of the future research priorities within this framework.

A model with households of multiple individuals would add detail to the model as well. But in such case, the specific decisions about how households form and make joint decisions about labor supply and household location would have to be modeled explicitly. Not only would this add a computational burden to an already intensive simulation exercise, but it would also shift the focus of this study towards household decision making, without necessarily changing the aggregate results on regional and national levels. On the other hand, new parameters would be introduced to simulate intra-household decisions.

Some of the assumptions are almost inevitable. For instance, the assumption over the bounded univariate distribution of individual skill deviation is necessary; while other bounded transformations could be used, the use of an unbounded, e.g., normal, distribution would essentially lead to some extreme draws, associated with negative effective labor supply and income.

Within the framework presented, we have utilized the assumption of myopic expectations. Another common approach is that of perfect foresight, where people are thought to have perfect information regarding future prices, wages and rental rates. One may note that, in the presented model, a steady state equilibrium under perfect foresight, would also constitute a steady state equilibrium under myopic expecta- tions, since myopic expectations are consistent with rational expectations in steady state. It is rather the transition path that would primarily be affected by the introduction of rational expectations, i.e., by iteratively applying the solution algorithm of section 3.1 and updating the agents expectations according to the equilibrium solution provided by the algorithm. Perfect foresight and the multiregional setting are the main modeling challenges for the future. 


\section{Appendix A: Parameters, Variables and}

Notation

Table 4: Parameter Values common to all simulation experiments

\begin{tabular}{cc}
\hline \hline Parameter & Value \\
\hline$\varphi^{0}$ & 1.00 \\
$\varphi_{1}$ & 1.00 \\
$\zeta$ & 0.35 \\
$\theta$ & 0.35 \\
$\eta$ & 0.30 \\
$\alpha$ & 0.6 \\
$\beta$ & 0.4 \\
$\delta$ & 0.95 \\
$\chi_{0}$ & 0.0 \\
$\chi_{1}$ & 0.0 \\
$\xi$ & 0.0
\end{tabular}


Table 5: Notation: Variables

\begin{tabular}{cc}
\hline$V$ & \\
$\Psi$ & Origin-Destination matrix of commuting times \\
$F$ & Origin-Destination matrix of commuting costs \\
$\mathrm{C}$ & Crigin-Destination matrix of household relocation costs \\
$\mathrm{L}$ & Labor \\
$\ell$ & leisure \\
$\bar{T}$ & Time period endowment (normalized to 1) \\
$P_{i}\left(P_{\mathrm{a}}\right)$ & Price index in residential region $i$ \\
$\mathrm{M}$ & Non-labor income (from land rents) \\
$\mathrm{S}$ & Savings \\
$\mathrm{w}$ & Competitive wage rate per period \\
$\mathrm{z}$ & Tax rate on labor income \\
$\mathrm{d}$ & Idiosyncratic skill deviation \\
$\mathrm{R}$ & World interest rate \\
$\mathrm{Z}$ & Per period income attached to an arbitrary wage offer \\
$\mathrm{u}$ & Utility function in the middle level \\
$U_{\mathrm{a}}$ & Maximum utility achieved for a given alternative, a. \\
$\mathrm{x}$ & The manufactured good produced in region 0 or 1. \\
$\mathrm{l}$ & housing (land) \\
$\mathrm{p}$ & Disaggregate price of commodity $x$. \\
$\mathrm{q}$ & land rent per unit. \\
$e^{*}$ & Minimum expenditure \\
$\mathrm{K}$ & Capital. \\
$Q_{j i}$ & Quantity sent from region $j$ for each unit of output received in $i($ Iceberg reciprocal). \\
$K_{\mathrm{G}}$ & Public capital. \\
$\hat{X}$ & Volume of trade. \\
$\hat{k}$ &
\end{tabular}

Table 6: Notation: Parameters

\begin{tabular}{cc}
\hline$\alpha$ & Capital share in production. \\
$\beta$ & Labor share in production. \\
$\delta$ & Discount factor. \\
$\epsilon$ & Error term in the RUM model of the upper level. \\
$\varepsilon$ & Line search scalar in the hybrid Newton method. \\
$\theta$ & Preference parameter for commodity 0 \\
$\eta$ & Preference parameter for commodity 1 \\
$\vartheta$ & Preference parameter for housing \\
$\lambda$ & The effect of all unobserved factors in the utility when living in the birthplace \\
$\mu$ & Lagrangian multiplier for the intertemporal budget constraint. \\
$\xi$ & Lagrangian multiplier for the non-negativity labor supply constraint. \\
$e_{b j}^{0}, e_{b j}^{1}$ & Bounding parameters for the distribution of skill in zone $j$ for those born in region $b$. \\
$\varsigma$ & Public capital parameter in the commuting time function. \\
$\mu, \sigma$ & Parameters of the Normal distribution. \\
$\varphi_{0}$ & Parameter for Consumption \\
$\varphi_{1}$ & Parameter for Leisure \\
$\chi_{0}, \chi_{1}$ & Parameters of the i.i.d. EVI distribution for the error terms. \\
$\omega$ & Public capital parameter in the transport cost function.
\end{tabular}


Table 7: Notation: Subscripts-Superscripts-Sets

\begin{tabular}{cc}
\hline & \\
\hline $\mathbf{a}$ & Arbitrary alternative for the young individual \\
$\hat{\mathbf{a}}$ & Arbitrary alternative for the old individual \\
$\mathbf{p}$ & Vector of local price indices \\
$\mathrm{I}$ & The set of residential zones \\
$\mathrm{J}$ & The set of employment zones \\
$\mathrm{R}$ & The set of retirement zones \\
$\mathrm{Y}$ & The set of young individuals \\
$\mathrm{O}$ & The set of old individuals \\
$\mathrm{i}$ & An arbitrary residential zone \\
$\mathrm{j}$ & An arbitrary employment zone \\
$\mathrm{r}$ & An arbitrary retirement zone \\
$\mathrm{n}$ & An arbitrary individual \\
$\mathrm{b}$ & Birth zone. \\
$N_{\text {set }}$ & Number of elements in an arbitrary set. \\
$\mathscr{C}$ & The set of simulated choices in each iteration round.
\end{tabular}




\section{Appendix B: Summary of key equations}

Table 8: Young consumers

Conditional (on a) utility function:

$\mathrm{u}=\vartheta+\varphi_{0} \log \left(C_{b n \mathbf{a}}^{t}\right)+\varphi_{1} \log \left(1-L_{b n \mathbf{a}}^{t}-v_{\mathbf{a}}^{t}\right)+\delta\left\{\vartheta+\varphi_{0} \log \left(C_{b n \mathbf{a}}^{t+1}\right)\right\}$

Conditional (on a) Euler equation.

$$
\frac{C_{b n \mathrm{a}}^{t+1 *}}{C_{b n \mathrm{a}}^{t *}}=\delta\left(1+R^{\mathrm{e} t+1}\right) \frac{P_{\mathrm{a}}^{t}}{P_{\mathrm{a}}^{\mathrm{e} t+1}}
$$

Conditional (on a) consumption/leisure:

$$
\frac{\ell_{b n \mathrm{a}}^{t *}}{C_{b n \mathrm{a}}^{t *}}=\frac{\phi_{1}}{\phi_{0}} \frac{P_{\mathrm{a}}^{t}}{w_{\mathrm{a}}^{t}\left(1-z^{t}\right)\left(1+d_{b n \mathrm{a}}\right)}
$$

Conditional (on a) stochastic intertemporal budget constraint: $P_{\mathbf{a}}^{\mathbf{e}^{(t+1)}} C_{b n \mathbf{a}}^{t+1}=\left(1+R^{\mathrm{e}(t+1)}\right) S_{b n \mathbf{a}}^{t}+M_{n}^{\mathrm{e}(t+1)}-F_{\mathbf{a}}^{t+1}$

Conditional (on a) savings equation:

$$
S_{b n \mathbf{a}}^{t}=\left(1-z^{t}\right) w_{\mathbf{a}}^{t}\left(1+d_{b n \mathbf{a}}\right) L_{b n \mathbf{a}}^{t}+M_{n}^{t}-P_{\mathbf{a}}^{t} C_{b n \mathbf{a}}^{t}-\psi_{\mathbf{a}}^{t}-F_{b \mathbf{a}}^{t}
$$

Conditional (on a) subutility function:

$$
C_{b n \mathbf{a}}^{t}=\left(x_{0(b n \mathbf{a})}^{t}\right)^{\zeta}\left(x_{1(b n \mathbf{a})}^{t}\right)^{\theta}\left(l_{b n \mathbf{a}}^{t}\right)^{\eta}
$$


Table 9: Old consumers

$$
\begin{aligned}
& \text { Conditional (on } \hat{\mathbf{a}} \text { ) utility function: } \\
& \mathrm{u}=\vartheta+\varphi_{0} \log \left(C_{b n \hat{\mathbf{a}}}^{t}\right) \\
& C_{b n \hat{\mathbf{a}}}^{t *}=\frac{\left(1+R^{t}\right) S_{n}^{t-1}+M_{n}^{t}-F_{\hat{\mathbf{a}}}^{t}}{P_{\hat{\mathrm{a}}}^{t}}
\end{aligned}
$$

Table 10: Firms

\begin{tabular}{c}
\hline $\begin{array}{c}\text { Production function: } \\
X_{j}^{t}=\left(K_{j}^{t}\right)^{\alpha}\left(L_{j}^{t}\right)^{\beta}\end{array}$ \\
Effective labor demand: \\
$L_{j \mathbf{D}}^{t}\left(w_{j}^{t}, R^{t} ; X_{j}^{t}\right)^{*}=X_{j}^{t}\left\{\frac{R^{t}}{w_{j}^{t}} \frac{\beta}{\alpha}\right\}^{\alpha}$ \\
Capital demand: \\
$K_{j \mathbf{D}}^{t}\left(w_{j}^{t}, R^{t} ; X_{j}^{t}\right)^{*}=X_{j}^{t}\left\{\frac{w_{j}^{t}}{R^{t}} \frac{\alpha}{\beta}\right\}^{\beta}$ \\
Cost function: \\
$C_{j}^{t}\left(w_{j}^{t}, R^{t} ; X_{j}^{t}\right)^{*}=X_{j}^{t}\left(R^{t}\right)^{\alpha}\left(w_{j}^{t}\right)^{\beta}\left\{\left(\frac{\beta}{\alpha}\right)^{\alpha}+\left(\frac{\alpha}{\beta}\right)^{\beta}\right\}$
\end{tabular}

Table 11: Government, Transport system and other key equations

$$
\begin{gathered}
\text { Balance equation: } \\
R^{t} K_{\mathrm{G}}^{t}=\sum_{n \in Y}\left\{L_{b n \mathbf{a}^{*}}^{* t}\left(1+d_{b n \mathbf{a}^{*}}\right) w_{\mathbf{a}^{*}}^{t} Z^{t}\right\}+\sum_{n \in Y} \psi_{\mathbf{a}^{*}}
\end{gathered}
$$

Elasticity of the iceberg reciprocal with respect to public capital:

$$
\mathscr{E}_{K_{\mathrm{G}}^{t}} Q_{01}^{t}=\frac{\omega A\left(K_{\mathrm{G}}^{t}\right)^{\omega}}{1+A\left(K_{\mathrm{G}}^{t}\right)^{\omega}}
$$

$$
\begin{gathered}
\text { Capital accumulation: } \\
K^{t+1}=\sum_{n \in Y}\left\{L_{b n \mathbf{a}^{*}}^{t *}\left(1+d_{b n \mathbf{a}^{*}}\right) w_{\mathbf{a}^{*}}^{t}\left(1-z^{t}\right)-P_{\mathbf{a}^{*}}^{t} C_{b n \mathbf{a}^{*}}^{t *}+M_{n}^{t}-\psi_{\mathbf{a}^{*}}-F_{i \mathbf{a}^{*}}\right\}
\end{gathered}
$$

Regional price index:

$$
P_{i}^{t}=\frac{p_{0 i}^{t \zeta} p_{1 i}^{t \theta} q_{i}^{t \eta}}{\zeta^{\zeta} \theta^{\theta} \eta^{\eta}}
$$




\section{References}

Abdel-Rahman, H. M. and P. Wang. 1995. Toward a general-equilibrium theory of a core-periphery system of cities. Regional Science and Urban Economics, 25(4):529-546. URL http://ideas.repec.org/a/eee/ regeco/v25y1995i4p529-546.html.

Acemoglu, D. 2009. Introduction to modern economic growth. Princeton and Oxford: Princeton University Press.

Agenor, P.-R. and B. Moreno-Dodson. 2006. Public infrastructure and growth: new channels and policy implications. Policy Research Working Paper Series 4064, The World Bank. URL http://ideas.repec.org/p/wbk/wbrwps/4064. html.

Anas, A. and Y. Liu. 2007. A regional economy, land use, and transportation model. Journal of Regional Science, 47(3):415-455. ISSN 1467-9787. doi: 10.1111/j.14679787.2007.00515.x. URL http://dx.doi.org/10.1111/j. 1467-9787.2007.00515.x.

Armington, P. S. 1969. A theory of demand for products distinguished by place of production. Staff Papers - International Monetary Fund, 16(1):pp. 159-178. ISSN 00208027. URL http://www.jstor.org/stable/3866403.

Artige, L. 2004. Endogenous growth and regional dynamics in an olg model with land. Discussion Papers 2004028, IRES Institut de Recherches Economiques et Sociales. URL http: //ideas.repec.org/p/ctl/louvir/2004028.html.

Judd, K. L. 1998. Numerical methods in economics. 0262100711. Cambridge, MA: The MIT Press. URL http: //ideas.repec.org/b/mtp/titles/0262100711.html.

McArthur, D., I. Thorsen, and J. Uboe. 2010. A microsimulation approach to modelling spatial unemployment disparities. Ph.D. thesis, Norwegian School of Economics and Business Administration.

Michel, P. and D. de la Croix. 2000. Myopic and perfect foresight in the olg model. Economics Letters, 67(1):53 - 60. ISSN 0165-1765. doi: 10.1016/S0165-1765(99)002463. URL http://www.sciencedirect.com/science/article/ pii/S0165176599002463.

Oosterhaven, J. and T. Knaap. 2003. Transport projects, programmes and policies: Evaluation needs and capabilities, chapter Spatial economic impacts of transport infrastructure investments, pp. 87-105. London: Ashgate.

Rietveld, P. 1989. Infrastructure and regional development: A survey of multiregional economic models. The Annals of Regional Science, 23(4):255-74. URL http://ideas.repec. org/a/spr/anresc/v23y1989i4p255-74.html.
Rioja, F. K. 1999. Productiveness and welfare implications of public infrastructure: a dynamic two-sector general equilibrium analysis. Journal of Development Economics, 58(2):387-404. URL http://ideas.repec.org/a/ eee/deveco/v58y1999i2p387-404.html.

Samuelson, P. A. 1954. The transfer problem and transport costs, ii: Analysis of effects of trade impediments. The Economic Journal, 64(254):pp. 264-289. ISSN 00130133. URL http://www.jstor.org/stable/2226834.

Seung, C. K. and D. S. Kraybill. 2001. The effects of infrastructure investment: A two-sector dynamic computable general equilibrium analysis for ohio. International Regional Science Review, 24(2):261-281. doi: 10.1177/016001701761013150. http://irx.sagepub.com/content/24/2/261.full.pdf+html, URL http://irx.sagepub.com/content/24/2/261.abstract.

Shapiro, C. and J. E. Stiglitz. 1984. Equilibrium unemployment as a worker discipline device. American Economic Review, 74(3):433-44. URL http://ideas.repec.org/a/aea/ aecrev/v74y1984i3p433-44.html.

Zhu, X., J. Van Ommeren, and P. Rietveld. 2009. Indirect benefits of infrastructure improvement in the case of an imperfect labor market. Transportation Research Part B: Methodological, 43(1):57-72. URL http://ideas.repec.org/a/eee/ transb/v43y2009ilp57-72.html. 